\title{
Vibration energy harvesting: A review
}

\author{
Anwesa Mohanty*, Suraj Parida, Rabindra Kumar Behera \\ and Tarapada Roy \\ National Institute of Technology, Rourkela, India \\ *anwesamohanty93@gmail.com
}

Received 24 June 2019; Revised 10 August 2019; Accepted 12 August 2019; Published 5 September 2019

\begin{abstract}
This study is based on energy harvesting from vibration and deals with the comparison of different techniques. In the present scenario, energy harvesting has drawn the attention of researchers due to a rapid increase in the use of wireless and small-scale devices. So, there is a huge thirst among scientists to develop permanent portable power sources. In the surroundings, a lot of unutilized energy is wasted which can be collected and used for power generation. Research works have been extensively carried out to develop energy harvesting devices catering to the increasing needs of being efficient and economical. Effective energy harvesting mainly depends on the design of the transducer. Different types of design techniques, material properties, and availability of energy harvesters are reviewed in this paper. The paper aims to explore the advantages and limitations of different energy harvesting principles, advances, and findings of the recent past. This study also discusses some of the key ideas for the enhancement of power output. This paper provides a broad view of the energy harvesting system to the learners, which will facilitate them to design more efficient energy harvesting devices by using different principles.
\end{abstract}

Keywords: Electromagnetic; piezoelectric; electrostatic; magnetostrictive.

\section{Introduction}

In the recent smart world, the importance of wirelessly connected system is felt more as the world requires to be converted into a global market through it in no time. Due to the advancement in technology such as wireless sensor networks (WSNs), ${ }^{1}$ micro-electromechanical systems (MEMS), ${ }^{2}$ and Internet of Things (IoT), the utilization of mobile energy sources is highly essential. Battery connectivity, wire connectivity, nonregenerated energy sources, etc. can solve the problem of these necessities. But due to some technical flaws, namely current leakages in the battery (in case of both used and unused), electricity resistance, and practical difficulties in case of connections through a wire, etc., there is an increasing need to create other efficient energy storage methodologies. The bottlenecks against the use of a present source of energy are limited availability of energy source, maintenance at a regular interval, restricted life cycle, labor constraints, and delay in disposal of related materials, etc. To overcome all these hurdles, an innovative idea for energy generation from the prevailing environmental sources has been fabricated to supplement the present technological demands without polluting the environment. Different options are available in the surrounding to harvest energy without hampering its cleanliness and keeping the environment intact. Hence, with environmental concerns and the global energy crisis, various sources of energy like wind, solar, geothermal, hydropower, and vibration, etc. can be considered to generate power. By considering different favorable factors like technological feasibility, cleanliness, developmental scope, and maintenance cost, etc., both solar and vibration source of energy are better focus areas for research. But while we observe technology maturity factor, the vibration energy source is the best for future research work. This can help not only to energize small-scale devices but also empower energyconsuming instruments in transport, infrastructures, and human movement.

Vibration energy harvesting is the technique to scavenge energy from the unwanted vibration occurrences in the environment. A large amount of vibration occurs due to the motion of vehicles on the bridges and working of various types of machinery in industries and buildings. These residual energies discharged into the surroundings may be considered as a wasted potential energy source. By using smart materials and adopting different techniques of energy harvesting, electrical energy can be harvested. As it is exploited from the environment belonging to nature and industry, it is considered as free energy. So vibration is an alluring source of energy to empower small-scale devices. It is nothing but the collection of traveling waves on solid materials. To convert mechanical to electrical energy, vibration movement has to be coupled with a generator by using the inertia of seismic mass. For this purpose, different transduction mechanisms have been designed.

Renewable energy harvesting plants using wind energy, solar energy, etc. can generate $\mathrm{kW}, \mathrm{MW}$ range of power and are called as macro-energy harvesting system whereas microenergy harvester (EH) which is based on vibration, generates

This is an Open Access article published by World Scientific Publishing Company. It is distributed under the terms of the Creative Commons Attribution 4.0 (CC BY) License which permits use, distribution and reproduction in any medium, provided the original work is properly cited. 


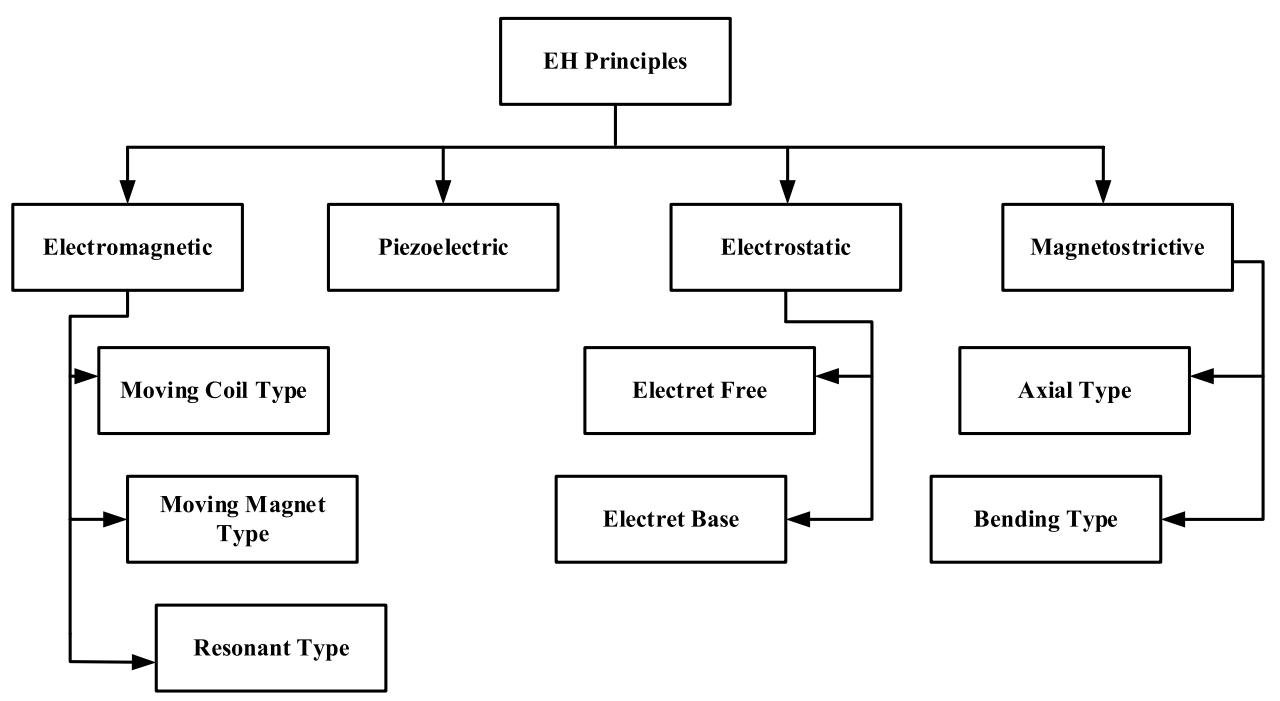

Fig. 1. Common principles used in VEH.

$\mathrm{mW}$ and $\mu \mathrm{W}$ range of power. However, the major issue of concern is to power wireless devices. Energy harvesting from a clean energy source of vibration gives a long-term solution to drive remote devices. So current research focuses on vibration energy generation as it is eco-friendly and viable with low installation and maintenance cost. Energy generated from this vibration $\mathrm{EH}(\mathrm{VEH})$ can be used in the functioning of health monitoring devices such as low power wearable sensor, ${ }^{3}$ electrocardiogram (ECG) machine, electronic microscope, serum analyzer, glucometer, treadmill, magnetic resonance imaging (MRI) machine, and autoanalyzer, etc. ${ }^{4}$ To improve power generation capacity, various strategies have been reported and reviewed in different studies. ${ }^{5,6}$ Some common principles to convert vibration energy to electricity are given in Fig. 1. Although it has not yet been possible to replace the batteries completely, a lot of research studies are being conducted to reduce its hazards towards the environment and the present invention will definitely be helpful to strengthen the previous research works making a mark in the field.

\section{Electromagnetic EH (EMEH)}

In EMEH, mechanical energy is converted to electrical energy during the occurrence of relative motion between the conductive coil and a magnetized body. The magnetic circuit which is implemented in this configuration for power generation requires a magnetic field. This is generated either by a permanent magnet or by an electromagnet. The permanent magnet is more suitable than electromagnet for low power devices as it does not require power input. These permanent magnets contain ferromagnetic or ferrimagnetic material. Due to the atoms containing unpaired electrons in a ferromagnetic material, it produces a net magnetic moment, whereas ferrimagnetic material contains the atom of opposing magnetic moments. Although ferromagnetic materials produce a strong electric field, they are commonly used, as they have higher electrical resistance, resulting in less eddy current effect. Generally, four types of magnets are present for the application: ceramic, neodymium iron boron, alnico, and samarium cobalt. ${ }^{7}$ VEH applications depend on properties such as magnetic field strength, coercive force, and flux density. Types of magnets and their characteristics and compositions are described in Table 1. Except for these materials, research is going on to fabricate micro-magnets (like FePt, CoPt) having high density. ${ }^{8,9}$ The high temperature annealing process is required for the materials to get optimum magnetic characteristics. ${ }^{10}$

Table 1. Composition and characteristics of different types of magnet.

\begin{tabular}{|c|c|c|}
\hline Magnets & Composition & Characteristics \\
\hline Ceramic (1950) & $\begin{array}{l}\text { - Iron and barium } \\
\left(\mathrm{BaFe}_{2} \mathrm{O}_{3}\right) \\
\text { - } \text { Strontium oxide } \\
\left(\mathrm{SrFe}_{2} \mathrm{O}_{3}\right)\end{array}$ & $\begin{array}{l}\text { Hard, brittle, low energy } \\
\text { product, flux density low }\end{array}$ \\
\hline $\begin{array}{l}\text { Neodymium Iron } \\
\text { Boron (1980) }\end{array}$ & $\begin{array}{l}\text { - Combination of } \\
\mathrm{Nd}, \mathrm{Fe} \text {, and B }\end{array}$ & $\begin{array}{l}\text { High magnetic field, } \\
\text { maximum energy } \\
\text { product, poor corrosion } \\
\text { resistance, low working } \\
\text { temperature }\end{array}$ \\
\hline Alnico (1940) & $\begin{array}{l}\text { - Combination of } \mathrm{Al} \text {, } \\
\mathrm{Ni}, \mathrm{Co}, \mathrm{Cu}, \mathrm{Fe}, \mathrm{Ti} \\
\text { (different } \\
\text { percentages) }\end{array}$ & $\begin{array}{l}\text { Less sensitivity to } \\
\text { temperature, good } \\
\text { corrosion resistance }\end{array}$ \\
\hline $\begin{array}{l}\text { Samarium Cobalt } \\
\text { (1970) }\end{array}$ & $\begin{array}{l}\text { - Combination of } \\
\text { Sm, Co }\end{array}$ & $\begin{array}{l}\text { High magnetic field, good } \\
\text { thermal stability, } \\
\text { moderate corrosion } \\
\text { resistance }\end{array}$ \\
\hline
\end{tabular}




\subsection{Principle}

The principle of EM generator is based on Faraday's law ${ }^{11}$ of electromagnetic induction which asserts direct proportionality of voltage to the change of magnetic flux linkage with respect to time. Therefore, the voltage developed in the coil is ${ }^{12}$

$$
V_{\text {coil }}=-\frac{d \phi}{d t}=-N\left(\frac{d \varphi}{d t}\right)
$$

where $N, \varphi$ is the number of turns in the conductive coil and average magnetic flux in single loop, respectively. $\phi$ is the total flux linkage and can be calculated as

$$
\phi=\sum_{i=1}^{N} \int_{A} B d A .
$$

Here, $d A$ is the change in the area, $B$ is the magnetic field vector and $i$ represents the number of turns. While the flux density is assumed to be uniform throughout the coil area, then the flux density becomes

$$
\phi=N B A \sin (\alpha) \text {. }
$$

And the resulting voltage is given by

$$
V=-N A \frac{d B}{d t} \sin (\alpha)
$$

where $\alpha$ denotes the angle between flux density direction and coil area.

However, the flux linkage gradient is mainly based on various parameters of system design such as types of magnets, its position in the system arrangement, and number of turns in the coil.

\subsection{Mechanism}

EMEH configuration is subdivided into three broad categories, namely moving coil type, moving magnet type, and resonant type. Moving magnet-type $\mathrm{EH}$ is more prone to catastrophic destruction compared to the other two types, while it comes near or in contact with the ferromagnetic substances. Even in case of the fixed magnet-type EH, the magnet can be exploited to attach the harvester to the ferromagnetic component. ${ }^{13}$ A common type of EM configuration is highlighted in Fig. 2. The power output does not only depend on the configuration but also depends on material properties and the size of transducer. ${ }^{14}$ Coil resistance is highly dependent on the number of turns in the coil and its technology. With an increased number of turns of coil used, there occurs enhancement of coil resistance, resulting in the cancellation of electromagnetic damping for wire-wound coil and lowering in damping in case of the planar micro-coil. Besides, this leads to an increase in voltage output. To enhance the effectiveness and efficiency of the EMEH, the researchers have focused on various parameters. Some of them are to decrease the resonant frequency and to widen the frequency bandwidth. The frequency of vibration that occurs

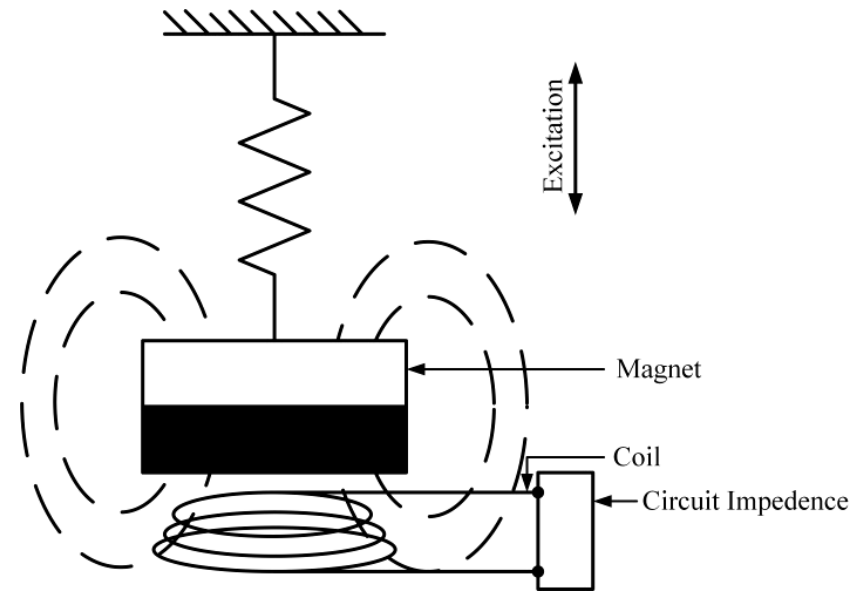

Fig. 2. Schematic diagram of EMEH.

due to daily household apparatus, human walking, around buildings, and dance floors ${ }^{15}$ is small. At the same time, some portable small-scale devices require small harvesters which function at low frequency. But the EH system with high natural frequency makes the collection of low frequency excitation from surrounding difficult for the harvester. ${ }^{16}$ This issue forced the researchers to design harvester of low working resonant frequency to generate ample power.

The first micro-scaled EMEH was designed by Shearwood and Yates in $1997 .{ }^{17,18}$ Using two wafers, a harvester was configured and fabricated. They found that at $4.4 \mathrm{kHz}$ resonance frequency, the RMS power is $0.3 \mu \mathrm{W}$. In this design, high resonant frequency is considered which results in low energy conversion efficiency. To reduce this problem, other researchers later tried to design harvester by reducing the resonance frequency up to a few hundred Hertz. Further, in 2003, a similar design was presented by Huang et al. ${ }^{19}$ It was observed that for $100 \mathrm{~Hz}$ resonant frequency, $1.4 \mu \mathrm{W}$ power was generated. A laser micro-machined EMEH with the volume of $1 \mathrm{~cm}^{3}$ was developed by Ching et al. ${ }^{20}$ to get optimal voltage output to operate low power integrated circuits and micro-sensor from nominal size harvester. In their extended work, they integrated the harvester with a power management circuit. Power harvested from this design can power the radio frequency transmission. ${ }^{21,22}$ Another micro-power EM generator was developed for low frequency excitation that occurs in the environment. ${ }^{23-25}$ Similarly, design of the EH model consisting of the cantilever beam, pick-up coil, magnet, and mechanical barrier arm were aimed for low frequency range, i.e., $1-10 \mathrm{~Hz}$ vibration energy harvesting. Scaling down of the dimension of the prototype was done for optimum power output. It was found that power harvested from it will be helpful to drive low power micro-system. ${ }^{26,27}$ The structure comprises of a clamped-free support-type cantilever beam. A major limitation of these micro-systems is the limited number of turns of the coil. Optimization was done by using the response surface method for performance improvement by changing the frequency of external excitation. ${ }^{28}$ 
A device with a single resonance frequency is good enough to harvest energy under a convenient range of narrow frequency band. But due to different physical parameters, when frequency mismatch occurs between environment and system, the system response decreases significantly. Due to this, it is required to develop multi-frequency EMEH by widening bandwidth. To resolve this problem, many authors have proposed different research. According to past research, some relevant methods are there to increase bandwidth. By introducing multi-degrees of freedom system in an excitation structure, bandwidth of the EH can be broadened. ${ }^{29,30} \mathrm{An}$ other method to make wide bandwidth is introducing nonlinearity in an energy harvesting system. Compared to the linear system, it performs well. Some techniques used for performance increment through the introduction of nonlinearity into the system are coupling between modes, hybrid transduction, tuning, and multi-modal arrays. ${ }^{31,32}$ In 2014, a novel EMEH was designed by Ooi and Gilbert $^{33}$ that implements dual resonator technique to improve the operating range of frequency. As shown in Fig. 3, the abovementioned study is designed consisting of two different resonator systems. Due to multi-vibration mode, several frequencies of different modes are adjusted to a particular range which results in broader bandwidth. ${ }^{34-37}$ A series of EH can be assimilated with different springs and mass to expansive bandwidth. ${ }^{38-40}$ As these harvesters have different frequencies individually, it exhibits a wide operating range of frequencies. Theoretical modeling and analysis were done to examine the vibration and dynamic behavior of the coupled electromagnetic system. The EH design was the combination of multiple subsystems so that multiple modes were generated. It was found that the average power generation by the EH varies considerably for each resonance. ${ }^{41}$ Two different prototypes were designed for output power enhancement of the energy harvesting device by integrating it to multifrequency MEMS. ${ }^{42}$ Energy harvesting can be done for a wide range of frequency by eliminating spring configuration from the EMEH. ${ }^{43-45}$ The most commonly used technique for this widening operation is tuning method. In this

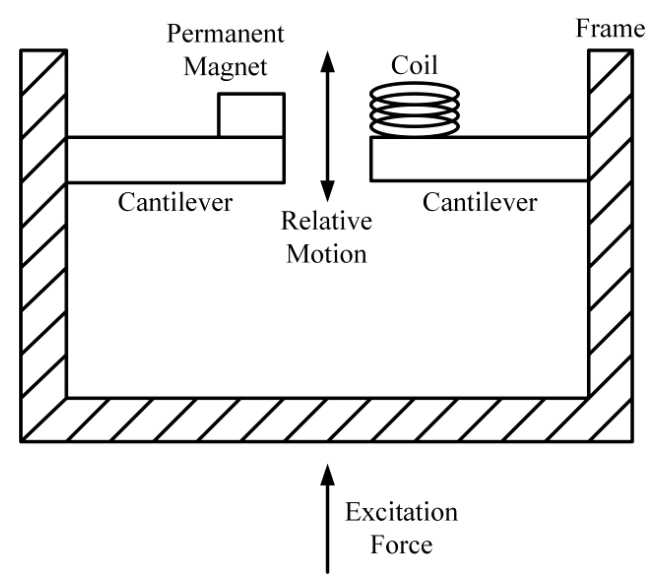

Fig. 3. Dual resonator EM generator. technique, modification of different parameters is done to equalize the resonance frequency of the system with surrounding frequency. It is of two types such as active and passive tuning. In the case of active tuning, the parameters are adjusted continually whereas in case of passive tuning, after adjustment of the parameter tuning, actuator achieves change in resonance frequency. ${ }^{46,47}$

EMEH has certain advantages over other EHs, such as no external voltage input is required and a good amount of power can also be generated from weak vibration. As power is directly proportional to the operating frequency, the frequency-up conversion is implemented to achieve the desired amount of average power from human body movement. ${ }^{48,49}$ Also due to frequency-doubling characteristics of some EMEH, more power is generated from low frequency. ${ }^{50}$ Contrarily, by introducing switching damping, the resonant frequency can be altered but some loss also occurs in power outcome. ${ }^{51}$ Optimal performance is obtained for the small value of EM damping in case of a linear system and large damping value for nonlinear ones. ${ }^{52}$ By dropping the size factor, benefits of EMEH abate due to windage loss and magnetic deterioration. However, fabrication of magnetic coil on micro- and nano-scales is an area of challenge due to the compact size and significant power raise with the input amplitude, especially with low-frequency vibrations. ${ }^{53-55}$ These EH can accumulate micro-energy and by using energy acquisition system, instantaneous charging power can be generated. In a practical case, $30.313 \mathrm{~mW}$ power is generated from bus vibration by adopting the above technique. ${ }^{56}$ The EMEH functions best when its size is larger and excitation is periodic in nature, but poor in case of random vibration. ${ }^{57,58}$

\section{Piezoelectric EH (PEH)}

PEH generally converts mechanical to electrical energy while deformation of the structures occurs. ${ }^{59}$ The piezoelectric effect is a unique material property which is divided into two types. One is the direct effect in which sensation of mechanical stress or strain generates an electric field across the material and acts as a sensor. The second one is the converse effect in which reversely applied electric field introduces deformation in the material and acts as an actuator. ${ }^{60,61}$ These two types of mechanisms are shown in Fig. 4 for better understanding. Such an effect is found in both natural and man-made materials. Each crystal of piezoelectric material is composed of a small, tetravalent metal ion placed inside a lattice of larger divalent metal ions and $\mathrm{O}_{2}$. Some familiar examples of these materials are Berlinite, Quartz, Lead Zirconate Titanate (PZT) and Aluminum Nitride. ${ }^{62}$ To make it more environmental friendly, new lead-free piezoelectric is developed, e.g., PE nanogenerators containing zinc nanowires $(\mathrm{ZnO}){ }^{63,64}$

Mostly all piezoelectric materials are brittle in nature. These materials are available in four types, namely single crystals, ceramics, polymers, and thin films. The piezoceramic element can be used for both low and high power 


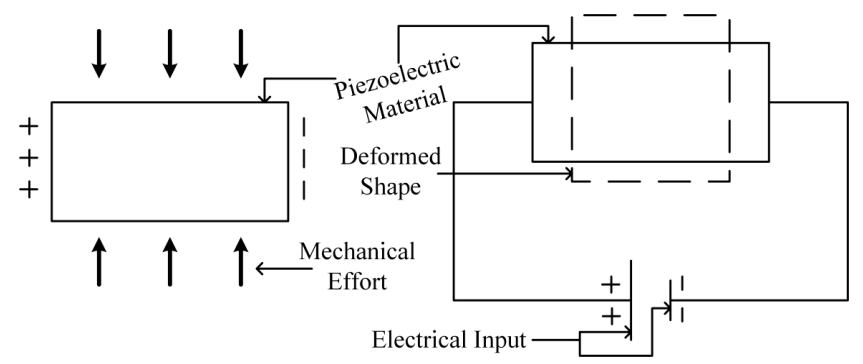

Fig. 4. Schematic diagram for two types of piezoelectric EH: (a) direct piezoelectric effect and (b) reverse piezoelectric effect.

applications. For example, PZT-5A, PZT-5H, and PZT-5J are used for low power application, and PZT-4 and PZT-8 are used for high power application. ${ }^{65}$ Porous PZT material has offered advantages like good capacitance and stiffness control. ${ }^{66}$ Some characteristics and applications of piezoceramic elements are given in Table 2. Like piezoelectric ceramics, piezoelectric polymers provide high energy density. But polymer-like polyvinylidene fluoride (PVDF) has a low coupling coefficient and possesses poor adhesion to the material, whereas PZT has a high coupling coefficient. Due to this property, PZT is preferable for energy harvesting. ${ }^{67,68}$ Single crystal PE materials have unique properties like longitudinal electromechanical coupling factor as 0.95 and $\mathrm{PE}$ coefficients between $1500 \mathrm{pC} / \mathrm{N}$ and $2500 \mathrm{pC} / \mathrm{N}$. PE thin films, due to their higher value of PE constant, are generally used as sensors and actuators whereas PZT thick films are widely developed to fabricate MEMS. Although there is a wide range of options for material selection, a suitable material for VEH is chosen by considering the product value of piezoelectric voltage constant and strain constant.

Table 2. Characteristics and applications of different piezoceramic element.

\begin{tabular}{|c|c|c|}
\hline Piezoceramics & Characteristics & Application \\
\hline PZT-5A & $\begin{array}{l}\text { High voltage sensitivity } \\
\text { and dielectric constant, } \\
\text { volume resistivity }\end{array}$ & $\begin{array}{l}\text { - Medical applications } \\
\text { - Low power transducers } \\
\text { - Flaw detection probes } \\
\text { - Piezoigniters }\end{array}$ \\
\hline PZT-5J & $\begin{array}{l}\text { High piezoelectric voltage } \\
\text { constant and high } \\
\text { permittivity }\end{array}$ & $\begin{array}{l}\text { - Hydrophones } \\
\text { - Fuses }\end{array}$ \\
\hline PZT-5H & $\begin{array}{l}\text { Extremely high } \\
\text { permittivity, coupling } \\
\text { coefficient, and } \\
\text { piezoelectric charge } \\
\text { coefficient }\end{array}$ & $\begin{array}{l}\text { - Field and level sensors } \\
\text { - Material imaging } \\
\text { applications. } \\
\text { - Atuator and } \\
\text { accelorometers }\end{array}$ \\
\hline PZT-4 & $\begin{array}{l}\text { High electro-mechanical } \\
\text { coupling coefficient } \\
\text { and low dielectric } \\
\text { losses under high } \\
\text { driving field and a high } \\
\text { coercive field }\end{array}$ & $\begin{array}{l}\text { - Ultrasonic cleaners } \\
\text { - High power electro- } \\
\text { acoustic devices and sonar } \\
\text { - Industrial equipment }\end{array}$ \\
\hline PZT-8 & Highest electrical drive & $\begin{array}{l}\text { - Ultrasonic surgery } \\
\text { - Ultrasonic mixing } \\
\text { - Ultrasonic welding }\end{array}$ \\
\hline
\end{tabular}

\subsection{Principle}

As per the connection between stress and the polarization direction of PE material, it can work in three different modes, namely d33, d31, and d15 modes. The PEH is said to operate in $\mathrm{d} 31$ and $\mathrm{d} 33$ modes, while PE material is exposed to bending stress. However, for d15 mode-operated PEH, piezomaterial is exposed to torsion stress. ${ }^{69}$ In d33 mode, external stress and the polarization direction are the same and for the case of $\mathrm{d} 31$, the direction of applied force or stress is perpendicular to the output voltage direction. ${ }^{65,70} \mathrm{PEH}$ based on $\mathrm{d} 33$ mode generates higher voltage while d31 mode configuration gives more current and power output due to its low matching impedance. ${ }^{71}$ In some PEH systems, d15 configuration is adopted due to its higher piezoelectric shear coefficient which highly affects energy conversion.

A torsion EH was designed and investigated by Kulkarni et $a .^{72}$ to study the power output of the shear mode configuration. From their simulation result, it is noted that torsion EH gives maximum voltage generation compared to d31 mode-based equivalent EH. Later in 2015, Malakooti and Sodano ${ }^{73}$ investigated the numerical model for both $\mathrm{d} 15$ and d31 configurations and observed 50\% more power output in case of d15 mode PEH. Among all three elements, d31 is most popularly used over d15 and d33, given its simple manufacturing. The attributes of $\mathrm{d} 33$ in terms of complexity of interdigital electrode fabrication and $\mathrm{d} 15$ which involves two electrodes for poling and charge collection separately make their usage increasingly difficult. ${ }^{74,75}$ However, for actuator application, d33 mode configuration is better than the other two modes. ${ }^{76,77} \mathrm{PEH}$ uses direct piezoelectric effect for working purpose which is represented by the following constitutive equation ${ }^{61}$ :

$$
\begin{aligned}
& S=s T+d E, \\
& D=d T+\varepsilon E .
\end{aligned}
$$

Here, $S$ is the strain tensor, $s$ is elastic compliance constant, $D$ is electric displacement, $d$ is piezoelectric constant, $T$ is stress tensor, $\varepsilon$ is permittivity constant, and $E$ is the electric field tensor. The mathematical modeling of electromechanical coupling is derived for PEH based on the constitutive equations given in Eqs. (5) and (6).

\subsection{Mechanism}

For PE energy harvesting systems, the beam is attached with either an active piezoelectric layer and one passive layer called as unimorph or two piezoelectric active layers on both sides of the passive layer called as bimorph. ${ }^{78,79}$ This general mechanism of biomorph is known as triple-layer bimorph. While the inner passive layer is not taken into consideration, it is called as double-layer bimorph. In the case of unimorph configuration shown in Fig. 5(a), a resistive load is connected to it followed by conductive electrodes that entirely cover both upper and lower sides of piezoelectric material. Whereas 


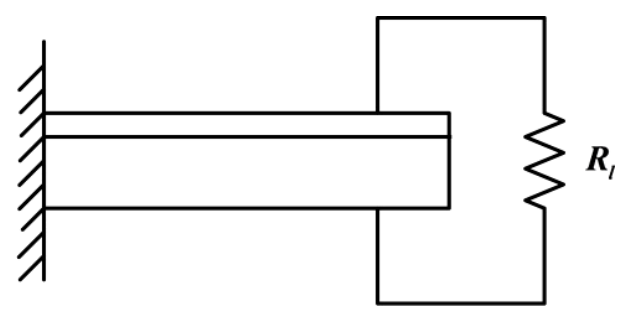

(a)

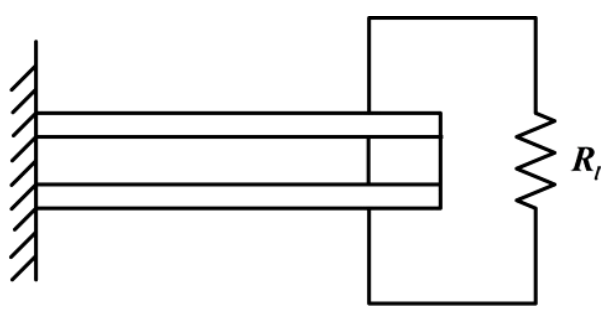

(b)

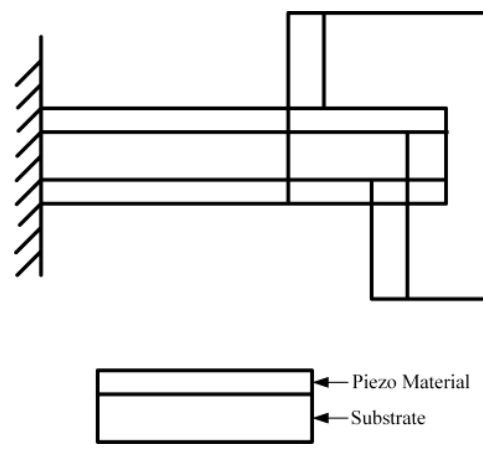

(c)

Fig. 5. PE EH configurations: (a) unimorph configuration, (b) bimorph configuration with series connection and (c) bimorph configuration with parallel connection.

in the case of bimorph, the connection can be series (as shown in Fig. 5(b)) or parallel (as shown in Fig. 5(c)) depending on the requirement of current and voltage. Voltage output is more in case of the series connection while the current output is more in case of parallel connection. The electromechanical coupling term $(v)$ for layers connected in series is $v=$ $2 \bar{e}_{31} b h_{p c}$ and coupling term $(v)$ for layers connected in series is $v=\bar{e}_{31} b h_{p c},{ }^{80}$ where $\bar{e}_{31}$ is the piezoelectric constant, $b$ is the width of the piezoelectric layer, and $h_{p c}$ is the distance between the center of piezoelectric and neutral axis. The calculation of various configuration parameters like rigidity and mass per unit length is mentioned in Table 3.

In recent years, significant improvements have occurred in the way of energy harvesting technology utilizing PE as a transducer. Priya ${ }^{81}$ reviewed recent advancements in the field of energy harvesting based on low profile PE transducers. He covered various designs of energy harvesting prototype as well as gave an elaborate idea of material selection to the readers. As per the study, the energy density of $\mathrm{PEH}$ is three to five times larger than other types of energy harvesting devices. Except this, many of the authors have studied the recent advances and various optimal approaches to design $\mathrm{EH}$ based on PE technology, which provide small steps towards the innovative design of PEH. ${ }^{82-84}$ Among different types of energy harvesting mechanisms, some of the popular configurations are piezoelectric mounted with a shoe, cantilever beam, and shell-type structures. Parasitic power generation was studied by Kymissis et al $^{85}$ who deigned three different EHs that can be placed inside the shoe. They have used unimorph configuration of both piezoceramic layer and multi-layer laminate of PVDF foil. But, it was difficult to configure it inside the shoe structure. At the same time due to its strong PE coupling and more conversion efficiency, it was able to generate significant power output for various low power applications. Later, Shenck and Paradiso ${ }^{86}$ used a compressible and nonbending bimorph configuration in place of unimorph. They compared the result with power generation of the shoe having PVDF stave. Similar works have been done for power generation from piezointegrated shoe structure using different PE materials. ${ }^{3,87}$

In Table $3, Y$ is young's modulus, $h$ is the thickness, $\rho$ is the mass density, $b$ is the width, $\bar{y}$ is the distance from the neutral axis. The subscripts $s$ and $p$ stand for substrate and piezoelectric material, respectively.

Table 3. Parameters for different configurations.

\begin{tabular}{lccr}
\hline Parameters & Unimorph & Double-layer bimorph & Triple-layer bimorph \\
\hline Rigidity $(E I)$ & $\frac{b}{3}\left[Y_{s}\left(3 h_{s} \bar{y}\left(\bar{y}-h_{s}\right)+h_{s}^{3}\right)+Y_{p}\left(3 h_{p}\left(\bar{y}-h_{s}\right)\left(\bar{y}-\left(h_{s}+h_{p}\right)\right)+h_{p}^{3}\right)\right]$ & $\frac{2 b Y_{p} h_{p}^{3}}{3}$ & $\frac{2 b}{3}\left(Y_{s} \frac{h_{s}^{3}}{8}+c_{11}^{E}\left(\left(h_{p}+\frac{h_{s}}{2}\right)^{3}-\frac{h_{s}^{3}}{8}\right)\right)$ \\
$\begin{array}{l}\text { Mass per unit } \\
\text { length }(\rho A)\end{array}$ & $b\left(\rho_{s} h_{s}+\rho_{p} h_{p}\right)$ & $2 b \rho_{p} h_{p}$ & $b\left(\rho_{s} h_{s}+2 \rho_{p} h_{p}\right)$ \\
\hline
\end{tabular}


EH consisting cantilever-type configuration can produce large deformation for small vibration and simultaneously, it has a simple design. In such cases, homogeneous and functionally graded (FG) beam, is considered. From different studies, it has been found that in the case of FG beam, more power is generated compared to homogeneous one. ${ }^{88,89} \mathrm{~A}$ simple beam integrated with self-powered PE sensor was theoretically modeled and experimented for power generation. It can be concluded from their analysis that the desired system can be able to power wireless devices effectively. ${ }^{90} \mathrm{~A}$ free-standing cantilever beam was designed having unimorph and multi-morph configurations. Conventional thick film technology was used for manufacturing purposes. ${ }^{91}$ Erturk and Inman ${ }^{92}$ in 2018 presented an exact analytical solution for the cantilever PEH. They have discussed several models and various correct and incorrect approaches to energy harvesting. Parametric case studies were conducted for unimorph case. It was found from the study that the locations of the electrodes are important for the electromechanical coupling and so as for electrical output. Much more analytical and experimental work regarding energy harvesting based on PE was done by Inman et al. ${ }^{93-96}$ in the past few years. They have discussed various principles, linear and nonlinear techniques of energy harvesting, power optimization technique which provides a broad view in the field of PEH to the new researchers. In 2010, Karami and Inman ${ }^{97}$ designed a zigzag microstructure for $\mathrm{EH}$ to generate efficient energy from a micro-generator. By using zigzag structure, the system was able to vibrate near the resonance. In some cases, a step was introduced in the design of the beam to increase the output power. In stepped beam, piezoelectric is attached to the stepped section to get optimal power output. ${ }^{98}$ To improve frequency flexibility and power output, a tip mass or magnet can be integrated into the cantilever structure. ${ }^{99-102}$ Because of the tip mass or tip magnet, both beam and piezoelectric oscillate resulting in imbalanced charges of piezomaterial. So, net positive and negative charges appear on opposite faces of the piezopatch and cause potential difference across its opposite faces. Further energy harvesting study is formulated by considering a system having multi-moving loads and masses. ${ }^{103}$ So, a considerable amount of energy can be harvested from practical cases like high way bridge, railway tracks, construction sites, etc. ${ }^{104}$ To harvest energy from such system, piezoelectric energy or thin piezoelectric patch can be directly attached at any position of the desired system. ${ }^{105}$ Although both the methods are fruitful to harvest energy, at the time of low vibrational frequencies, it is difficult to excite the harvester attached to the system. Hence, to improve the performance of harvesters for the efficient power output, some techniques such as multi-modal energy harvesting, use of magnetoelectric composites, self-tuning, frequency pumping, and wide bandwidth transducer ${ }^{7}$ are adopted. Multi-modal energy harvesting technique is the concept of combining two or more energy harvesting schemes or harvesting energy from two or more energy sources. ${ }^{106}$
A convenient example of multi-modal EH is a system considering a spiral-shaped cantilever beam with four permanent magnets and magnetoelectric transducers. This spiral structure contributes to exhibit multi-modal responses whereas magnet acts as proof mass and interacts with transducer. ${ }^{107}$ In the $\mathrm{PEH}$, nonlinearities can be introduced to increase the energy extraction abilities of harvester under monomodal and multi-modal excitation. ${ }^{108}$ Stanton et al. modeled the firstever principle-based nonlinear PE response and highlighted the importance of nonlinearity in the PEH. The theoretical analysis was done for both linear and nonlinear systems. ${ }^{109}$ To enhance the performance of the $\mathrm{EH}$, it is synchronized with switch harvesting by inductor method with and without threshold detection. ${ }^{110}$ The advanced design of an EH having distributed piezoelectric material is configured to maximize power output by reducing voltage cancellation. Due to the excellent performance of this system, it can be used in various systems having multi-modal vibrating skins like aircraft skin. ${ }^{111}$ Research is going on to develop multi-modal EH integrated with wireless transreceiver. ${ }^{12,113}$ The use of magnetoelectric composites enhances the efficiency of the $\mathrm{EH}$ system. This composite is the combination of piezoelectric and magnetostrictive phases which provide the advantage in the conversion of the magnetic field into stress. ${ }^{114}$ Its magnetoelectric properties depend on phases, shape, and size of the structure having various phases in a different form. In case of optimum power output, self-tuning property of the $\mathrm{EH}$ is highly desirable. ${ }^{115-117}$ Some of the familiar methods are used to change the frequency, like using the shunt in the circuit and by implementing cascading electrical connections. However, it has some drawbacks because of its complex electronic configuration and requirement of several transducers. Another approach for effective power generation is frequency pumping. It is achieved by increasing more deflections at a particular time. ${ }^{118,119}$ As the major issue faced in VEH is narrow bandwidth, so the most common and efficient scheme which is focused now a days is widening it to enhance the frequency. ${ }^{120}$ Several simple techniques can be adopted to attain wide bandwidth such as mechanical impact and frequency up conversion. ${ }^{121,122}$ In addition to this, modification of the acceleration which is applied to the system also has an impact on the wideband operation. ${ }^{122}$ On the other hand, it has a drawback of low power density.

The main advantage of PEH is compact size, i.e., dimension of the piezopatch is very thin and hence the whole system is more simple and small compared to other EH. ${ }^{123}$ Also, small-scale piezoelectric transduction is more effective than electromagnetic transduction. So, it can be used in a compact structure like wind turbine ${ }^{124}$ and airflow $\mathrm{EH},{ }^{78}$ sound wave $\mathrm{EH},{ }^{125,126} \mathrm{EH}$ based on the impact of raindrop, ${ }^{127-129}$ etc. It is one of the leading systems given its uncomplicated structure and high power-generation efficiency. ${ }^{130}$ Energy harvested and dissipated in this process does not only depend on the rectified voltage but also depends on the ratio between the rectifier voltage drop and 
the open-circuit voltage. ${ }^{131}$ To improve output obtained from piezoelectric, the voltage multiplier circuit is implemented in the system of EH. ${ }^{129}$ However, one of the thoughtful problems is to achieve maximum efficiency of power generation. $^{132}$ To maximize efficiency, the frequency modification of the system is done by extending frequency bandwidth. ${ }^{31,99,133}$

\section{Electrostatic EH (ESEH)}

Electrostatic is also known as triboelectric and the electrostatic charge transfer is known as triboelectricity. It produces energy with motion between two surfaces of a charged capacitor, resulting in changes in capacitor potential difference and delivers static electricity. ESEH converts vibrational energy to electrical energy by the usage of various converters which are basically a two-step conversion, ${ }^{134}$ i.e., electrical effect and mechanical effect. The performance of the EH not only depends on the configuration but also depends on the nature of materials. As most of the materials in the surroundings have triboelectrification effect, therefore, material availability and the area of choice are huge. Basically, triboelectric materials are arranged according to their behavior towards losing or gaining electrons which are known as triboelectric series. In this series, materials are placed by means of their tendency towards losing electrons that are charged positively and gain electrons that are charged negatively. However, some materials in between these listed materials show a weak tendency for both the ways. ${ }^{135,136}$ Research is going on by selecting different types of polymer materials from different positions of the series to know the amount of charge transfer and for the enhancement of power output of EH. ${ }^{137}$ In 2012, Fan et al. ${ }^{138}$ gave a comparison study by taking two pairs of polymer materials. They found that the materials which are far away in series can generate more power than the materials which are near to each other. In addition to this, by changing the structure of the surfaces can be modified to increase the contact area and triboelectric effect. ${ }^{136,139,140}$ Lee et al. ${ }^{141}$ designed a nanogenerator which was based on pendulum motion to power small LED lights. Here, they enhanced the triboelectric effect by using the surface structure of plant design management system (PDMS).

\subsection{Principle}

ESEH having two dielectrics of permittivities $\varepsilon_{1}$ and $\varepsilon_{2}$ and thicknesses $t_{1}$ and $t_{2}$ is driven to physical contact by connecting them through the electrode and circuit impedance. Once this is connected with a charged electrode, electrostatic charge flows to the surface. Initially, the surface is partially charged which forms a triboelectric potential layer and that static charge results in surface charge density to be saturated. It does not depend on the distance between the two dielectrics. The flow of electrons occurrs due to the formation of the triboelectric field which leads the electrons to gather at

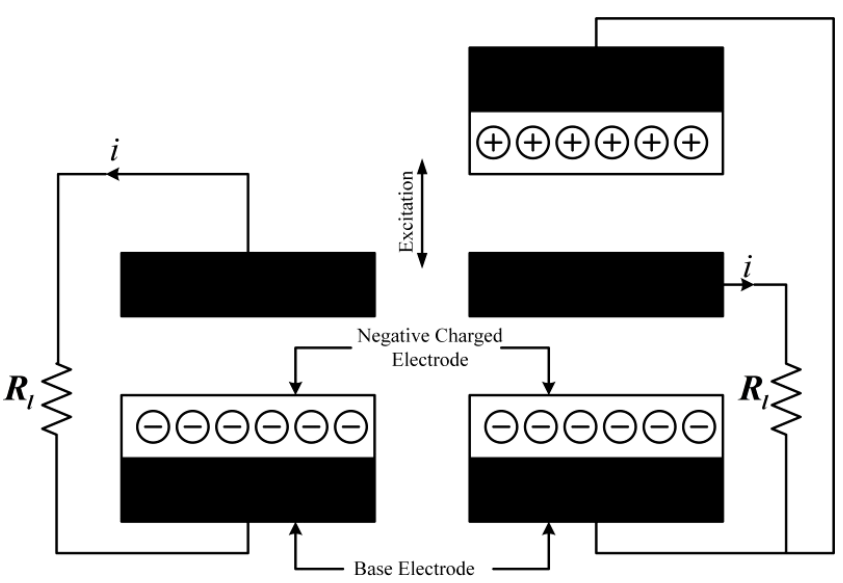

Fig. 6. General working principle for ESEH.

electrodes $\left(\sigma_{I}\right)$. Thus, this potential field acts as a pump and pushes the electrons to flow through external load while capacitance variation occurs. ${ }^{142}$ So for the dielectrics, the value of the electric field can be calculated by $E_{1}=\sigma_{I} / \varepsilon_{1}, E_{2}=$ $\sigma_{I} / \varepsilon_{2}$ whereas for gap, it is calculated as $E=$ $\left(\sigma_{I}-\sigma_{c}\right) / \varepsilon_{0},{ }^{143}$ where $\varepsilon_{0}$ is the space permittivity.

Hence the potential difference can be given as

$$
V=\sigma_{I}\left[t_{1} / \varepsilon_{1}+t_{2} / \varepsilon_{2}\right]+z\left[\sigma_{1}-\sigma_{c}\right] / \varepsilon_{0} .
$$

Here, $z$ is the distance between two electrodes. The basic ESEH model is depicted in Fig. 6.

\subsection{Mechanism}

Variable capacitors are mainly divided into three types: variable dielectric constant capacitor, variable gap capacitor, and variable area capacitor. In a variable dielectric constant capacitor, enhancement of power output is done due to change in dielectric material. ${ }^{144,145}$ Salem et al. ${ }^{146}$ designed a micro-scale EH having a switchable dielectric constant capacitor to enhance the power output. It is observed from their study that a thousand times more power is generated in this configuration than the conventional EH. Various studies have been done on the variable gap capacitor where vibration is primarily produced due to the variation of gap-closing layout for power scavenging. ${ }^{147,148}$ Guillemet et al. ${ }^{148}$ presented an analytical formulation to study the efficiency of $\mathrm{EH}$ by using two different types of gap-closing capacitors. One is out-ofplane and another is an in-plane capacitor. Tsutsumino et al. ${ }^{149}$ developed a numerical model of the in-plane capacitor model and validated it with the experimental result. Later in the study, they demonstrated an electrode arrangement to reduce the damping effect. In the variable area capacitor, vibration occurs in the opposite direction of plates due to which capacitance changes and electricity is produced. ${ }^{150,151}$ Sarafian and York $^{152}$ in 2008 introduced an innovative way to design a capacitor to alter its overlapping capacitive area. They studied the effect of change in 
overlapping area under constant angular velocity and acceleration. Recently, Sequeira et al. ${ }^{153}$ tried to discover the optimized plate pattern of the capacitor by using the topological optimization method to enhance the average output power. Various mechanisms are used to design ESEH such as continuous electret-based systems, switched constant charge system, and switched constant voltage system. ${ }^{154,155}$ Boisseau et al. ${ }^{156}$ presented an overview of electrostatic energy conversion using both electrate free and electratebased mechanism. They have discussed different past research work based on the mentioned mechanisms to study the limitations and perspectives of ESEH to maximize the power generation. Torres and Rincon-Mora ${ }^{157}$ designed a voltage constrained ESEH to operate in volume constraint environment effectively to extract energy from the work done by the plate of the capacitor. Their study mainly aimed to assess the availability of energy before and after the power generation to establish the energy conversion technique for the enhancement of energy output. There are two types of ESEH, i.e., electret-free and electret-based ESEH. In case of electret-free $\mathrm{EH}$, energy conversion cycle is used to convert mechanical energy into electricity either by charge or voltage constraint cycle. Although the charge constraint cycle is more popular than voltage constraint cycle due to its easy implementation, the maximum output power is obtained in case of voltage-constrained cycle. ${ }^{25,151}$ In case of electret-based EH, electret (dielectric material) layers are polarized to capacitors for the conversion of energy. ${ }^{158,159}$ Basset et al. ${ }^{160}$ fabricated a silicon-based ESEH to harvest energy without considering an electret layer. $61 \mathrm{nW}$ power was noted at frequency of $250 \mathrm{~Hz}$ and excitation level of $0.25 \mathrm{~g}$ by using $60 \mathrm{M} \Omega$ resistive load. In 1992, Tada ${ }^{161}$ designed an experimental setup of electret generator to study its operating principle. Maximum $1.02 \mathrm{~mW}$ power was extracted using the designed EH. ESEH was first introduced with the implementation of MEMS devices in 2001 by using digital control system. ${ }^{134}$ Tashiro et $a{ }^{162}$ assessed variable capacitance-type $\mathrm{EH}$ to drive cardiac pacemaker to replace the battery. Later micro-machined ESEH based on rotational electrate mechanism was developed by Boland et al. ${ }^{163}$ Genda et al. ${ }^{164}$ designed a novel electric circuit along with the efficient electret-based EH to get the optimal power output. Further by using corona discharge, they developed an electret charging device. Hoffman et $a l .{ }^{165}$ studied the modeling and characterization of microgenerator adopting ES mechanism. A maximum estimated power output of $3.5 \mu \mathrm{W}$ was observed when system vibrated at its resonance frequency for $13 \mathrm{~g}$ input excitation. In 2010, Nguyen et al. ${ }^{166}$ presented an ESEH model based on MEMS utilizing nonlinear spring to widen the frequency bandwidth. It was found from the study that with the softening of spring, more power is extracted than a linearized system for sufficient random vibration. As it produced high voltage output and low current, it is not possible to utilize this in any electronic appliances. So, power converters like the power management control circuit are used to develop sensor. It is used for the modulation of resonant frequency, power conversion, and energetic buffering.

However, the configuration of ESEH mainly depends on four basic modes: vertical contact separation mode, lateral sliding mode, free-standing turboelectric layer mode, and single electrode mode. Two types of mechanisms can be used in the case of vertical contact and lateral sliding. One is dielectric to dielectric mechanism and the other one is metal to dielectric mechanism. ${ }^{167}$ Vertical contact separation mode EH generally implements vertical polarization. In this type, two different dielectric materials are used which are attached to the pair of electrodes. ${ }^{168,169}$ In 2013, Hou et al. ${ }^{170}$ designed a triboelectric nanogenerator whose working principle was based on contact separation mode. They have used this EH to harvest energy effectively from human footfall and it is observed that it can light up 30 white light-emitting diode (LED) lamps. Further, structural integration of a nanogenerator having multi-layered disk is done. Due to its multi-layer configuration, it can generate good electrical output. ${ }^{171}$ In the case of lateral sliding mode, lateral polarization occurs. This mechanism can generate continuous electricity for high frequency. Nevertheless, it has surface friction loss due to sliding effect. ${ }^{172,173}$ To harvest energy from a freely moving object, single electrode mode is used; it is designed in such a way that the conduction line is not connected with the dielectric pair. Here, one triboelectric surface is taken with which electrode is connected and another one is human skin. ${ }^{174,175}$ Its mechanism and working principle are easy and it can be easily integrated with other electronic devices. ${ }^{176}$ Kaur et al. ${ }^{177}$ presented effective energy harvesting by using nanogenerator which is based on the single-electrode mode. They used composite as a binder and compared the results with the polymer. They found that due to the use of composite, charge transfer capability increases. In 2017, Park et al. ${ }^{178}$ designed a nanogenerator of single electrode mode which can be applied to wearable products. They used silicon rubber as a negative dielectric material and the conductive thread was taken as an electrode. Electricity was produced due to the interaction of human skin and the silicon layer. But in this case, the outcome of electricity is very low. In freestanding triboelectric layer mode, one dielectric material is free and another pair of dielectric material is fixed and attached to electrodes. In this configuration, the lateral sliding occurs between free and paired electrodes. It shows a good conversion efficiency. ${ }^{179,180}$ Design of EH can also be based on a combination of different modes to enhance the output power. In recent years, research is carried on to get optimal power output by hybridizing triboelectric material with piezoelectric and electromagnetic materials. ${ }^{181,182}$ Shao et al. $^{183}$ have succeeded to generate energy as a practical source which will be able to deliver power to supercapacitor and LED bulbs.

An external voltage source is required for ESEH, which generates small energy density. The major advantage of it is the production of extremely high voltage due to high internal impedance as compared to PEH for which it can be transmitted 
to a long distance without any power loss. ${ }^{184}$ Due to no usage of smart materials like piezopatches, magnetostrictive, shape memory alloy, and optoelectronics, etc., lifespan is infinite with low system cost and adjustable coupling coefficient. It is mostly used for small-scale purposes. Charging and discharging of the capacitor take place in electret-free electrostatic VEH. ${ }^{185}$ Whereas in the case of electret-based electrostatic $\mathrm{VEH}$, direct conversion of mechanical to electrical energy without any cycle of charges and discharges take place. In this kind, two types of converters are used, i.e., passive power converters and active power converters. Efficiency is higher in active power converter whereas power conversion is simple in case of passive power converter. ${ }^{156}$

\section{Magnetostrictive EH (MSEH)}

Magnetostrictive material (MSM) has the property to produce kinetic energy from magnetic energy. EH using MS effect generates electricity from mechanical vibration in two steps. First mechanical energy is converted to magnetic energy through the magneto-mechanical coupling and then using electromagnetic coupling, this magnetic energy is converted to electrical energy. ${ }^{186}$ It follows the Villari/Magnetoelastic effect. Magnetostrictive materials contain small ferromagnetic materials like iron, cobalt, nickel. These materials have a small magnetic moment. While the magnetic field is applied, an axial magnetic moment is superimposed with an atomic magnetic moment. Due to this method, material either shrinks or stretches. ${ }^{187}$ Numerical modeling and experimentation have already been done by different researchers to know the MS response of the materials. ${ }^{188,189}$ Polymer-based composites are also used as MSM. When this material comes in contact with the magnetic field, the dimension as well as the elastic and magnetic properties of it are changed simultaneously when it comes to the contact of the magnetic field. Different MS bulk materials are Terfenol-D, Galfenol, Alfenol, Cobalt Ferrite, Metglas 2605SC Amorphous alloy, etc. ${ }^{186,190}$ and various MS polymer composites are Nickel/ Vinyl ester, Galfenol flakes/epoxy, $\mathrm{CoO}-\mathrm{Fe}_{2} \mathrm{O}_{3} /$ Phenol, Galfenol particles/Epoxy, Silicon steel/Epoxy, Carbonyl iron/ Silicon, etc. To enhance the power of EH, MSM can be transversely annealed by a strong magnetic field. Polymer composites are better for the use in EH than MSM due to their high resistivity, low weight, improved mechanical property, and good frequency response. ${ }^{186} \mathrm{MS}$ polymer composites are used to sense ultrasonic wave in actuators, biomedical applications, sensors, vibration isolation and control, and health monitoring, etc. Composition and characteristics of some MSM are given in Table 4. EH using MS mechanism is easily compacted with other EH mechanisms. ${ }^{191}$

\subsection{Principle}

As there is a motion between internal electrons of ferromagnetic atoms, ferromagnetic materials easily change its
Table 4. Composition and characteristics of different types of MSM.

\begin{tabular}{|c|c|c|}
\hline MS bulk material & Composition & Characteristics \\
\hline $\begin{array}{l}\text { Metglas2605SC } \\
\quad(1970)\end{array}$ & $\mathrm{Fe}, \mathrm{Si}, \mathrm{B}$ & $\begin{array}{l}\text { - High energy conversion } \\
\text { efficiency } \\
\text { - Long life cycle } \\
\text { - Lack of depolarization } \\
\text { - Stable in strong vibration }\end{array}$ \\
\hline Galfenol (1998) & $\mathrm{Ga}, \mathrm{Fe}$ & $\begin{array}{l}\text { - Piezomagnetic coefficient } \\
\text { is high } \\
\text { - Excellent machinability } \\
\text { - Inverse magnetostrictive } \\
\text { effect is high }\end{array}$ \\
\hline Terfeno-D (1970) & $\mathrm{Tb}, \mathrm{Dy}, \mathrm{Fe}$ & $\begin{array}{l}\text { - Magnetostriction effect is high } \\
\text { - High energy density } \\
\text { - Low Young's modulus }\end{array}$ \\
\hline Carbonyl Iron (1925) & $\mathrm{Fe}, \mathrm{C}$ & $\begin{array}{l}\text { - Stable in high temperature } \\
\text { - Stable in magnetic flux level }\end{array}$ \\
\hline
\end{tabular}

shape and size while the external magnetic field is applied to it. This effect of the magnetic field is known as Joule's effect. On the other hand, while mechanical force or vibration is applied to magnetostrictive material, the orientation of magnetic field changes which results in a change in magnetic flux, which is well known as the "Villari Effect". Due to this change in magnetic flux with respect to time, electromotive force is induced which leads to generation of electricity. Energy conversion of MSEH follows Faraday's law. In an MSEH, the coil is placed around the MS core. When mechanical stress is applied to the EH, change in flux density of MS core helps to produce a potential difference. This voltage is proportional to the change in flux of the coil and the number of turns of the coil. The voltage generated by the MS core can be calculated by

$$
V=2 \pi f n b s,
$$

where $f$ is the first resonance frequency; $n$ is the number of turns in the coil; $b$ is the variation of flux density, $s$ is the cross-sectional area of the core.

The power generated is given by

$$
P=V^{2} / R
$$

where $R$ is the resistance of the coil.

The performance of this type of $\mathrm{EH}$ is represented by following constitutive equation ${ }^{190}$ :

$$
B=d_{33}^{*} \sigma+\mu^{\sigma} H,
$$

where $B$ represents magnetic flux, $d_{33}^{*}$ is the change in flux with stress at a constant $H, \sigma$ is the stress, and $\mu^{\sigma}$ is the relative magnetic permeability at constant stress.

\subsection{Mechanism}

In the past decades, MS sensors were used to sense the timedependent mechanical stress or strain. Various mechanisms and principles of MS sensor having MS transducer of 


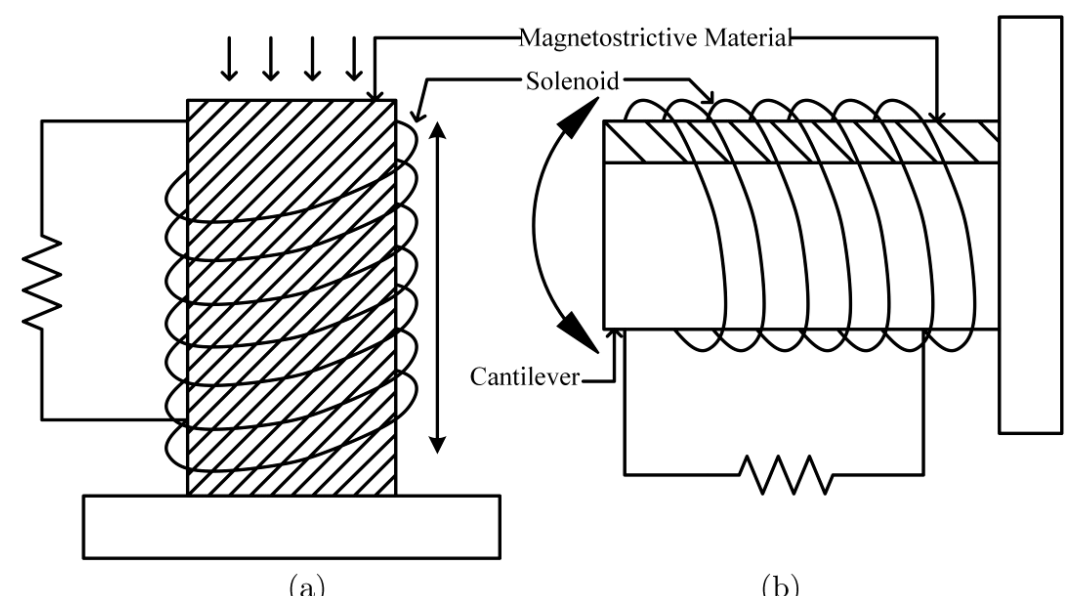

(a)

(b)

Fig. 7. Configuration of two types of MSEH: (a) axial type and (b) bending type.

different MS materials were studied. ${ }^{192,193}$ Theoretical study of sensor mechanism was elaborately described by Kwun and Bartel $^{194}$ which will be helpful for the future EH design. Considering stress state, MSEH is subdivided as the axial type and bending type which is presented in Fig. 7. The main application of axial-type harvester is to extract electrical energy from impact vibration. However, it has some drawbacks: limitation in frequency bandwidth and it requires a large amount of axial force. Yan and $\mathrm{Li}^{195}$ in 2011 proposed a hybrid EH configuration of magnetostrictive and electromagnetic ones to generate energy from human walking impact by varying air gap. In a further study, they designed an axial EH by introducing cap amplifier and variable air gap in the design to enhance the energy harvesting capacity. ${ }^{196,197}$ Mohammadi and Esfandiari ${ }^{198}$ studied a theoretical model of MSEH using strain energy method. Later, they compared the output power and voltage result with the PEH. It was observed that in the case of MSM, more power is generated. A realistic MSEH model was designed by taking Galfenol specimen as a core substance. A similar experiment was conducted in 2017 by Jafari et al. ${ }^{199}$ to harvest energy from low frequency excitation. The considered model was a cantilever coated with metglas covered by a coil. Both base excitation and free vibration analysis were performed to generate optimal power. In case of bending-type $\mathrm{EH}$, there is no limitation of force direction as it can collect energy from any vibrating surfaces. To improve the performance of MSEH, authors have considered various factors such as energy conversion efficiency, power density, axial effectiveness, generalized effectiveness, etc. ${ }^{186}$ Performance of EH using Galfenol MSM was studied of bending-type EH. It was observed from the experiment that, by reducing resonance frequency, conversion efficiency increases. ${ }^{200}$ Recently, Dey et al. $^{200}$ made an experimental prototype of MSEH to scavenge electricity from low frequency excitation taking irongallium as the core material. They found that power generated from the model can be able to power the micro-sensors. It was found that for $30 \mathrm{~Hz}$ frequency, conversion efficiency was $49 \%$. By taking an idea from $\mathrm{PEH}$, a frequency up-conversion technique was implemented to create MSEH. It was able to harvest energy from the excitation under $10 \mathrm{~Hz}$. They found that $5.3 \mathrm{~mW}$ power was delivered under finger tapping which can power 10 LED bulbs. ${ }^{201}$ The mathematical formulation of MSEH combined with nonlinear energy source was formulated to study the nonlinear pumping phenomenon. ${ }^{202}$ This leads to vibration superposition and efficient power output. $\mathrm{Xu}$ et al. ${ }^{203}$ extended 'a similar model by introducing a nonlinear output frequency response.

The characteristics' study of the direct and inverse effect of MSEH by using Prandtl-Ishlinskii model was done previously by different authors. The main loss factors such as hysteresis and eddy current loss of the EH devices were highlighted with different plots. ${ }^{204,205}$ Due to inductive characteristics of MSM harvester, it does not work well under high resistive load condition. $^{206}$ The main drawback of this harvester is the pickup coil dimension. But for most of the cases, MSEH produces higher power density than other EH at low frequency. ${ }^{199}$ Due to this, power output is higher in the case of MSEH. MS harvester has some other advantages like no external power source is required, no depolarization and aging problem, high conversion efficiency and high flexibility survival in strong vibration. It has an ultra-high coupling coefficient which is

Table 5. Comparison of different principle's outcome.

\begin{tabular}{lcccc}
\hline Principles & Electromagnetic & Piezoelectric & Electrostatic & Magnetostrictive \\
\hline Common material & $\begin{array}{c}\text { Neodymium iron boron } \\
\text { Voltage output }\end{array}$ & PZT & Conductive capacitor & Metglas, Terfenol-D \\
\hline
\end{tabular}


greater than 0.9. The major drawbacks of this system are difficulty in integration with MEMS ${ }^{207}$ and it can only produce considerable power near system resonance. Comparison of various principle outcomes is shown in Table 5 .

\section{Conclusion}

This paper discussed the development in VEH mechanism adopting different harvesting principles, its advantages, and drawbacks. In the past few years, a lot of work has been done to generate effective power output by introducing improvements such as innovative design to reduce the weight and size of the harvester, an addition of proof mass to increase strain, and introducing nonlinearity of the system. ${ }^{101,208,209}$ In today's world, the major challenge is to find out a more reliable and effective way to generate more voltage output from a low frequency range. Most of the latest research studies have focused on improving the conversion efficiency of $\mathrm{EH}$ by using different configurations and energy removal techniques. With the advances in technology, not only small-scale EHs but also large-scale VEHs provide promising solutions to energy crisis. Approximately, $85 \mathrm{~kW}$ power can be produced from 76 storied building vibration when wind load is applied. ${ }^{210}$ Compared to other storage devices like a battery, such EHs are maintenance-free, environmental-friendly, and have more life span.

Further research work is carried on for hybrid and broadband $\mathrm{EH}$ mechanisms as various energy sources are compatible with vibration energy to create a hybrid system. However, this type of system is more complex and cost-inefficient. ${ }^{50,101}$ In the future, emphasis should be given to harvest a significant amount of energy from raindrop, sound wave, flow-induced vibration, vortex-induced vibration, etc. Future research goal should be to develop more effective storing circuits and to find out more new materials for achieving better performance. These EHs are not only a good substitution to the battery but also a new alternative to encourage sources of green energy which are efficient and selfsufficient with varied applications.

\section{References}

${ }^{1}$ P. Pillatsch, E. M. Yeatman, A. S. Holmes and P. K. Wright, Wireless power transfer system for a human motion energy harvester, Sens. Actuators A Phys. 244, 77 (2016).

${ }^{2}$ S. Azizi, A. Ghodsi, H. Jafari and M. R. Ghazavi, A conceptual study on the dynamics of a piezoelectric MEMS (Micro Electro Mechanical System) energy harvester, Energy 96, 495 (2016).

${ }^{3}$ J. Zhao and Z. You, A shoe-embedded piezoelectric energy harvester for wearable sensors, Sensors (Switzerland) 14, 12497 (2014).

${ }^{4}$ A. Shin et al., A MEMS magnetic-based vibration energy harvester, J. Phys. Conf. Ser. 1052, 012082 (2018).

${ }^{5} \mathrm{R}$. L. Harne and K. W. Wang, A review of the recent research on vibration energy harvesting via bistable systems, Smart Mater. Struct. 22, 023001 (2013).
${ }^{6}$ D. Zhu, M. J. Tudor and S. P. Beeby, Strategies for increasing the operating frequency range of vibration energy harvesters: A review, Meas. Sci. Technol. 21, 022001 (2010).

${ }^{7}$ S. Priya and D. J. Inman, Energy Harvesting Technologies (Springer, New York, 2009).

${ }^{8}$ F. M. F. Rhen, G. Hinds, C. O'Reilly and J. M. D. Coey, Electrodeposited FePt films, IEEE Trans. Magn. 39, 2699 (2003).

${ }^{9}$ L. Vieux-Rochaz et al., Electrodeposition of hard magnetic CoPtP material and integration into magnetic MEMS, J. Micromech. Microeng. 16, 219 (2006).

${ }^{10}$ D. P. Arnold, Review of microscale magnetic power generation, IEEE Trans. Magn. 43, 3940 (2007).

${ }^{11}$ T. I. Zohdi, Electromagnetic Properties of Multiphase Dielectrics. Vol. 64, (Springer, Berlin, 2012).

${ }^{12}$ C. R. Saha, T. O'Donnell, N. Wang and P. McCloskey, Electromagnetic generator for harvesting energy from human motion, Sens. Actuators A Phys. 147, 248 (2008).

${ }^{13}$ F. U. Khan, Electromagnetic energy harvester for harvesting acoustic energy, Indian Acad. Sci. 9, 397 (2016), doi: 10.1007/ s12046-016-0476-9.

${ }^{14}$ D. Spreemann and Y. Manoli, Electromagnetic Vibration Energy Harvesting Devices, Vol. 35, (Springer, Netherlands, 2012).

${ }^{15}$ J. W. Matiko, N. J. Grabham, S. P. Beeby and M. J. Tudor, Review of the application of energy harvesting in buildings, Meas. Sci. Technol. 25, 012002 (2014).

${ }^{16}$ K. Najafi, T. Galchev, E. E. Aktakka, R. L. Peterson and J. McCullagh, Microsystems for energy harvesting, 2011 16th Int. Solid-State Sensors, Actuators and Microsystems Conf. TRANSDUCERS'11 (IEEE, New York, 2011), pp. 1845-1850, doi: 10.1109/TRANSDUCERS.2011.5969888.

${ }^{17}$ C. B. Williams et al., Development of an electromagnetic microgenerator, IEE Proc. Circuits Dev. Syst. 148, 337 (2001).

${ }^{18}$ C. Shearwood and R. B. Yates, Development of an electromagnetic micro-generator, Electron. Lett. 33, 1883 (1997).

${ }^{19}$ W. S. Huang, K. E. Tzeng, M. C. Cheng and R. S. Huang, Design and fabrication of a vibrational micro-generator for wearable MEMS, Proc. Eurosensors XVII (Institute of Electrical and Electronics Engineers, 2003), pp. 695-697.

${ }^{20}$ N. N. H. Ching, H. Y. Wong, W. J. Li, P. H. W. Leong and Z. Wen, A laser-micromachined multi-modal resonating power transducer for wireless sensing systems, Sens. Actuators A Phys. 97-98, 685 (2002).

${ }^{21}$ J. M. H. Lee, S. C. L. Yuen, W. J. Li and P. H. W. Leong, Development of an AA size energy transducer with micro resonators, Proc. 2003 Int. Symp. Circuits and Systems, 2003. ISCAS '03, Vol. 4, (IEEE, New York, 2003), pp. IV-876-IV-879.

${ }^{22}$ Harvesting ambient radio frequency electromagnetic energy for powering wireless electronic devices, sensors and sensor networks and applications thereof (2006).

${ }^{23}$ I. Sari, T. Balkan and H. Külah, An electromagnetic micro power generator for low-frequency environmental vibrations based on the frequency upconversion technique, J. Microelectromech. Syst. 19, 14 (2010).

${ }^{24} \mathrm{H}$. Kulah and K. Najafi, Method and micro power generator for generating electrical power from low frequency vibrational energy (2004). Patent.

${ }^{25}$ H. Kulah and K. Najafi, Energy scavenging from low-frequency vibrations by using frequency up-conversion for wireless sensor applications, IEEE Sens. J. 8, 261 (2008). 
${ }^{26}$ Ö. Zorlu, E. T. Topal and H. Kulah, A vibration-based electromagnetic energy harvester using mechanical frequency up-conversion method, IEEE Sens. J. 11, 481 (2011).

${ }^{27}$ S. D. Moss, O. R. Payne, G. A. Hart and C. Ung, Scaling and power density metrics of electromagnetic vibration energy harvesting devices, Smart Mater. Struct. 24, 023001 (2015).

${ }^{28} \mathrm{~J}$. Seo et al., Optimization and performance improvement of an electromagnetic-type energy harvester with consideration of human walking vibration, J. Korean Phys. Soc. 68, 431 (2016).

${ }^{29}$ S.-J. Chen and J.-Y. Wu, Fabrication of a 2-DOF electromagnetic energy harvester with in-phase vibrational bandwidth broadening, Smart Mater. Struct. 25, 095047 (2016).

${ }^{30} \mathrm{~B}$. Yang et al., Electromagnetic energy harvesting from vibrations of multiple frequencies, J. Micromech. Microeng. 19, 035001 (2009).

${ }^{31} \mathrm{~W}$. Yang and S. Towfighian, A hybrid nonlinear vibration energy harvester, Mech. Syst. Signal Process. 90, 317 (2017).

${ }^{32}$ N. Tran, M. H. Ghayesh and M. Arjomandi, Ambient vibration energy harvesters: A review on nonlinear techniques for performance enhancement, Int. J. Eng. Sci. 127, 162 (2018).

${ }^{33}$ B. L. Ooi and J. M. Gilbert, Design of wideband vibration-based electromagnetic generator by means of dual-resonator, Sens. Actuators A Phys. 213, 9 (2014).

${ }^{34}$ K. Tao, S. Liu, S. W. Lye, J. Miao and X. Hu, A threedimensional electret-based micro power generator for low-level ambient vibrational energy harvesting, J. Micromech. Microeng. 24, 065022 (2014).

${ }^{35} \mathrm{~K}$. Tao et al., A novel two-degree-of-freedom MEMS electromagnetic vibration energy harvester, J. Micromech. Microeng. 26, 035020 (2016).

${ }^{36} \mathrm{H}$. Liu et al., Feasibility study of a 3D vibration-driven electromagnetic MEMS energy harvester with multiple vibration modes, J. Micromech. Microeng. 22, 125020 (2012).

${ }^{37}$ H. Liu, L. Dhakar and C. Lee, Ultra-broadband electromagnetic MEMS vibration energy harvesting, J. Phys. Conf. Ser. 476, 012049 (2013).

${ }^{38}$ A. R. M. Foisal, C. Hong and G.-S. Chung, Multi-frequency electromagnetic energy harvester using a magnetic spring cantilever, Sens. Actuators A Phys. 182, 106 (2012).

${ }^{39}$ I. Sari, T. Balkan and H. Kulah, An electromagnetic micro power generator for wideband environmental vibrations, Sens. Actuators A Phys. 145-146, 405 (2008).

${ }^{40}$ H. Xue, Y. Hu and Q.-M. Wang, Broadband piezoelectric energy harvesting devices using multiple bimorphs with different operating frequencies, IEEE Trans. Ultrason. Ferroelectr. Freq. Control 55, 2104 (2008).

${ }^{41}$ C. G. Cooley, Vibration properties of and power harvested by a system of electromagnetic vibration energy harvesters that have electrical dynamics, Mech. Syst. Signal Process. 94, 237 (2017).

${ }^{42}$ D. Mallick, P. Constantinou, P. Podder and S. Roy, Multifrequency MEMS electromagnetic energy harvesting, Sens. Actuators A Phys. 264, 247 (2017).

${ }^{43} \mathrm{M}$. Han et al., Springless cubic harvester for converting three dimensional vibration energy, 2014 IEEE 27th Int. Conf. Micro Electro Mechanical Systems (MEMS) (IEEE, New York, 2014), pp. 425-428. doi: 10.1109/MEMSYS.2014.6765667.

${ }^{44} \mathrm{~S}$. H. Chae et al., Electromagnetic vibration energy harvester using springless proof mass and ferrofluid as a lubricant, J. Phys. Conf. Ser. 476, 012013 (2013).
${ }^{45}$ Z. Hadas and C. Ondrusek, Nonlinear spring-less electromagnetic vibration energy harvesting system, Eur. Phys. J. Spec. Top. 224, 2881 (2015).

${ }^{46}$ S. Roundy and Y. Zhang, Toward Self-tuning Adaptive VibrationBased Microgenerators, ed. S. F. Al-Sarawi, Vol. 5649, (International Society for Optics and Photonics, 2005), pp. 373.

${ }^{47}$ L. Tang, Y. Yang and C. K. Soh, Toward broadband vibrationbased energy harvesting, J. Intell. Mater. Syst. Struct. 21, 1867 (2010).

${ }^{48}$ M. A. Halim, H. Cho and J. Y. Park, Design and experiment of a human-limb driven, frequency up-converted electromagnetic energy harvester, Energy Convers. Manag. 106, 393 (2015).

${ }^{49}$ M. A. Halim and J. Y. Park, Modeling and experiment of a handy motion driven, frequency up-converting electromagnetic energy harvester using transverse impact by spherical ball, Sens. Actuators A Phys. 229, 50 (2015).

${ }^{50} \mathrm{X}$. Dai, An vibration energy harvester with broadband and frequency-doubling characteristics based on rotary pendulums, Sens. Actuators A Phys. 241, 161 (2016).

${ }^{51}$ B. L. Ooi, J. M. Gilbert and A. R. A. Aziz, Switching damping for a frequency-tunable electromagnetic energy harvester, Sens. Actuators A Phys. 234, 311 (2015).

${ }^{52}$ J. M. Kluger, T. P. Sapsis and A. H. Slocum, Robust energy harvesting from walking vibrations by means of nonlinear cantilever beams, J. Sound Vib. 341, 174 (2015).

${ }^{53}$ A. Haroun, I. Yamada and S. Warisawa, Micro electromagnetic vibration energy harvester based on free/impact motion for low frequency-large amplitude operation, Sens. Actuators A Phys. 224, 87 (2015).

${ }^{54}$ A. Haroun, I. Yamada and S. Warisawa, Study of electromagnetic vibration energy harvesting with free/impact motion for low frequency operation, J. Sound Vib. 349, 389 (2015).

${ }^{55}$ A. R. M. Siddique, S. Mahmud and B. Van Heyst, Energy conversion by 'T-shaped' cantilever type electromagnetic vibration based micro power generator from low frequency vibration sources, Energy Convers. Manag. 133, 399 (2017).

${ }^{56}$ N. Zhao, H. Luo, P. Liang and M. Zhou, The design and implementation of electromagnetic vibration energy acquisition system, Energy Procedia 136, 34 (2017).

${ }^{57}$ M. A. Halim, H. Cho, M. Salauddin and J. Y. Park, A miniaturized electromagnetic vibration energy harvester using fluxguided magnet stacks for human-body-induced motion, Sens. Actuators A Phys. 249, 23 (2016).

${ }^{58}$ W. Wang, J. Cao, N. Zhang, J. Lin and W.-H. Liao, Magneticspring based energy harvesting from human motions: Design, modeling and experiments, Energy Convers. Manag. 132, 189 (2017).

${ }^{59}$ J. M. Ramírez, C. D. Gatti, S. P. Machado and M. Febbo, An experimentally validated finite element formulation for modeling 3D rotational energy harvesters, Eng. Struct. 153, 136 (2017).

${ }^{60}$ L. H. Fang, S. I. S. Hassan, R. B. A. Rahim and M. F. A. Malek, A study of vibration energy harvester, ARPN Journal of Engineering and Applied Sciences, 11, 5028 (2016).

${ }^{61}$ K. V. Srikanth, State of art: Piezoelectric vibration energy harvesters, Mater. Today Proc. 4, 1091 (2017).

${ }^{62}$ C. R. Bowen, V. Y. Topolov and H. A. Kim, Piezoelectric mechanical energy harvesters and related materials, Modern Piezoelectric Energy-Harvesting Materials, Springer Series in Materials Science (Springer International Publishing, 2016), pp. 113-138. 
${ }^{63}$ Q. Liao et al., Flexible piezoelectric nanogenerators based on a fiber/ZnO nanowires/paper hybrid structure for energy harvesting, Nano Res. 7, 917 (2014).

${ }^{64}$ Qiu, Y. et al., Flexible piezoelectric nanogenerators based on $\mathrm{ZnO}$ nanorods grown on common paper substrates, Nanoscale 4, 6568 (2012).

${ }^{65}$ X. Xu, D. Cao, H. Yang and M. He, Application of piezoelectric transducer in energy harvesting in pavement, Int. J. Pavement Res. Technol. 11, 388 (2017).

${ }^{66}$ G. Martínez-Ayuso, M. I. Friswell, S. Adhikari, H. H. Khodaparast and C. A. Featherston, Energy harvesting using porous piezoelectric beam with impacts, Procedia Eng. 199, 3468 (2017).

${ }^{67} \mathrm{C}$. Wei and X. Jing, A comprehensive review on vibration energy harvesting: Modelling and realization, Renew. Sustain. Energy Rev. 74, 1 (2017).

${ }^{68}$ I. Jung, Y.-H. Shin, S. Kim, J. Choi and C.-Y. Kang, Flexible piezoelectric polymer-based energy harvesting system for roadway applications, Appl. Energy 197, 222 (2017).

${ }^{69}$ V. Kulkarni, R. Ben-Mrad and S. E. Prasad, A torsion based shear mode piezoelectric energy harvester for wireless sensor modules, Volume 4B: Dynamics, Vibration, and Control (ASME, 2014), p. V04BT04A053, doi: 10.1115/IMECE2014-37640.

${ }^{70}$ S. O. R. Moheimani and A. J. Fleming, Piezoelectric Transducers for Vibration Control and Damping. Advances in Industrial Control (Springer-Verlag, 2006).

${ }^{71}$ J. C. Park, J. Y. Park and Y.-P. Lee, Modeling and characterization of piezoelectric d33-mode MEMS energy harvester, J. Microelectromech. Syst. 19, 1215 (2010).

${ }^{72}$ V. Kulkarni, R. Ben-Mrad, S. E. Prasad and S. Nemana, A shearmode energy harvesting device based on torsional stresses, IEEE/ ASME Trans. Mechatron. 19, 801 (2014).

${ }^{73}$ M. H. Malakooti and H. A. Sodano, Piezoelectric energy harvesting through shear mode operation, Smart Mater. Struct. 24, 055005 (2015).

${ }^{74}$ N. W. Hagood, R. Kindel, K. Ghandi and P. Gaudenzi, Improving transverse actuation of piezoceramics using interdigitated surface electrodes, Smart structures and materials 1993: Smart Structures and Intelligent Systems, eds. N. W. Hagood and G. J. Knowles, Vol. 1917, (International Society for Optics and Photonics, 1993), pp. 341-352.

${ }^{75} \mathrm{~W}$. K. Wilkie et al., Low-cost piezocomposite actuator for structural control applications, Smart Structures and Materials 2000: Industrial and Commercial Applications of Smart Structures Technologies, ed. J. H. Jacobs, Vol. 3991 (International Society for Optics and Photonics, 2000), pp. 323-334.

${ }^{76} \mathrm{O}$. Bilgen, Y. Wang and D. J. Inman, Electromechanical comparison of cantilevered beams with multifunctional piezoceramic devices, Mech. Syst. Signal Process. 27, 763 (2012).

${ }^{77} \mathrm{~S}$. Koganezawa et al., Dual-stage actuator system for magnetic disk drives using a shear mode piezoelectric microactuator, IEEE Trans. Magn. 35, 988 (1999).

${ }^{78}$ Y. Tsujiura et al., Airflow energy harvester of piezoelectric thinfilm bimorph using self-excited vibration, Sens. Actuators A Phys. 261, 295 (2017).

${ }^{79}$ A. M. Matos, J. M. Guedes, K. P. Jayachandran and H. C. Rodrigues, Computational model for power optimization of piezoelectric vibration energy harvesters with material homogenization, Comput. Struct. 192, 144 (2017).
${ }^{80}$ A. Erturk and D. J. Inman, Piezoelectric Energy Harvesting (Wiley, Chichester, 2011).

${ }^{81}$ S. Priya, Advances in energy harvesting using low profile piezoelectric transducers, J. Electroceram. 19, 167 (2007).

${ }^{82}$ S. R. Anton and H. A. Sodano, A review of power harvesting using piezoelectric materials (2003-2006), Smart Mater. Struct. 16, R1 (2007).

${ }^{83}$ S. W. Ibrahim and W. G. Ali, A review on frequency tuning methods for piezoelectric energy harvesting systems, J. Renew. Sustain. Energy 4, 062703 (2012).

${ }^{84}$ A. Khan, Z. Abas, H. Soo Kim and I. K. Oh, Piezoelectric thin films: An integrated review of transducers and energy harvesting, Smart Mater. Struct. 25, 053002 (2016).

${ }^{85} \mathrm{~J}$. Kymissis, C. Kendall, J. Paradiso and N. Gershenfeld, Parasitic power harvesting in shoes, Digest of Papers. Second Int. Symp. Wearable Computers (Cat. No.98EX215) (IEEE, New York, 1998), pp. 132-139, doi:10.1109/ISWC.1998.729539.

${ }^{86}$ N. S. Shenck and J. A. Paradiso, Energy scavenging with shoemounted piezoelectrics, IEEE Micro 21, 30 (2001).

${ }^{87}$ J. G. Rocha, L. M. Goncalves, P. F. Rocha, M. P. Silva and S. Lanceros-Mendez, Energy harvesting from piezoelectric materials fully integrated in footwear, IEEE Trans. Ind. Electron. 57, 813 (2010).

${ }^{88}$ A. R. Biswal, T. Roy, R. K. Behera, P. K. Parida and S. K. Pradhan, Finite element based modeling of a piezolaminated tapered beam for voltage generation, Procedia Eng. 144, 613 (2016).

${ }^{89}$ A. R. Biswal, Geometric nonlinear finite element and genetic algorithm based vibration energy harvesting from functionally graded nonprismatic piezolaminated beams (2017).

${ }^{90}$ N. G. Elvin, A. A. Elvin and M. Spector, A self-powered mechanical strain energy sensor, Smart Mater. Struct. 10, 293 (2001).

${ }^{91}$ S. L. Kok, N. M. White and N. R. Harris, Fabrication and characterization of free-standing thick-film piezoelectric cantilevers for energy harvesting, Meas. Sci. Technol. 20, 124010 (2009).

${ }^{92}$ A. Erturk and D. J. Inman, A distributed parameter electromechanical model for cantilevered piezoelectric energy harvesters, J. Vib. Acoust. 130, 041002 (2008).

${ }^{93}$ A. Erturk and D. J. Inman, Issues in mathematical modeling of piezoelectric energy harvesters, Smart Mater. Struct. 17, 065016 (2008).

${ }^{94}$ D. N. Betts, H. A. Kim, C. R. Bowen and D. J. Inman, Optimal configurations of bistable piezo-composites for energy harvesting, Appl. Phys. Lett. 100, 114104 (2012).

${ }^{95}$ A. Erturk, P. A. Tarazaga, J. R. Farmer and D. J. Inman, Effect of strain nodes and electrode configuration on piezoelectric energy harvesting from cantilevered beams, J. Vib. Acoust. 131, 011010 (2009).

${ }^{96}$ H. A. Sodano, G. Park and D. J. Inman, Estimation of electric charge output for piezoelectric energy harvesting, Strain 40, 49 (2004).

${ }^{97}$ M. A. Karami and D. J. Inman, Analytical modeling and experimental verification of the vibrations of the zigzag microstructure for energy harvesting, J. Vib. Acoust. 133, 011002 (2011).

${ }^{98}$ R. Usharani, G. Uma, M. Umapathy and S.-B. Choi, A new piezoelectric-patched cantilever beam with a step section for high 
performance of energy harvesting, Sens. Actuators A Phys. 265, 47 (2017).

${ }^{99}$ L. Dhakar, H. Liu, F. E. H. Tay and C. Lee, A new energy harvester design for high power output at low frequencies, Sens. Actuators A Phys. 199, 344 (2013).

${ }^{100}$ J. Jung, P. Kim, J.-I. Lee and J. Seok, Nonlinear dynamic and energetic characteristics of piezoelectric energy harvester with two rotatable external magnets, Int. J. Mech. Sci. 92, 206 (2015).

${ }^{101}$ P. Firoozy, S. E. Khadem and S. M. Pourkiaee, Power enhancement of broadband piezoelectric energy harvesting using a proof mass and nonlinearities in curvature and inertia, Int. J. Mech. Sci. 133, 227 (2017).

${ }^{102}$ J. Q. Liu et al., A MEMS-based piezoelectric power generator array for vibration energy harvesting, Microelectronics J. 39, 802 (2008).

${ }^{103}$ Y. Amini, M. Heshmati, P. Fatehi and S. E. Habibi, Piezoelectric energy harvesting from vibrations of a beam subjected to multimoving loads, Appl. Math. Model. 49, 1 (2017).

${ }^{104}$ L. Zuo and X. Tang, Large-scale vibration energy harvesting. J. Intell. Mater. Syst. Struct. 24, 1405 (2013).

${ }^{105}$ Zhang, H. Xiang and Z. Shi, Mechanism exploration of piezoelectric energy harvesting from vibration in beams subjected to moving harmonic loads, Compos. Struct. 179, 368 (2017).

${ }^{106}$ S. Liu, Q. Cheng, D. Zhao and L. Feng, Theoretical modeling and analysis of two-degree-of-freedom piezoelectric energy harvester with stopper, Sens. Actuators A Phys. 245, 97 (2016).

${ }^{107} \mathrm{X}$. Bai et al., Multi-modal vibration energy harvesting utilizing spiral cantilever with magnetic coupling, Sens. Actuators A Phys. 209, 78 (2014).

${ }^{108} \mathrm{~S}$. Dhote, Z. Yang and J. Zu, Modeling and experimental parametric study of a tri-leg compliant orthoplanar spring based multi-mode piezoelectric energy harvester, Mech. Syst. Signal Process. 98, 268 (2018).

${ }^{109}$ S. C. Stanton, A. Erturk, B. P. Mann and D. J. Inman, Nonlinear piezoelectricity in electroelastic energy harvesters: Modeling and experimental identification, J. Appl. Phys. 108, 074903 (2010).

${ }^{110} \mathrm{M}$. Lallart, Nonlinear technique and self-powered circuit for efficient piezoelectric energy harvesting under unloaded cases, Energy Convers. Manag. 133, 444 (2017).

${ }^{111} \mathrm{~S}$. Lee and B. D. Youn, A new piezoelectric energy harvesting design concept: Multimodal energy harvesting skin, IEEE Trans. Ultrason. Ferroelectr. Freq. Control 58, 629 (2011).

${ }^{112}$ A. Didioui, Energy-aware transceiver for energy harvesting wireless sensor networks, doctoral disseration, Université Rennes 2014.

${ }^{113}$ J. Iannacci, G. Sordo, E. Serra and U. Schmid, A novel MEMSbased piezoelectric multi-modal vibration energy harvester concept to power autonomous remote sensing nodes for Internet of Things (IoT) applications, 2015 IEEE Sensors (IEEE, New York, 2015), pp. 1-4, doi: 10.1109/ICSENS.2015.7370550.

${ }^{114}$ J. Ma, J. Hu, Z. Li and C.-W. Nan, Recent progress in multiferroic magnetoelectric composites: From bulk to thin films, $A d v$. Mater. 23, 1062 (2011).

${ }^{115}$ L. Gu and C. Livermore, Passive self-tuning energy harvester for extracting energy from rotational motion, Appl. Phys. Lett. 97, 081904 (2010).

${ }^{116}$ C. G. Gregg, P. Pillatsch and P. K. Wright, Passively self-tuning piezoelectric energy harvesting system, J. Phys. Conf. Ser. 557, 012123 (2014)
${ }^{117}$ Y. Cheng, Study on efficient piezoelectric energy harvesting with frequency self-tuning (2015).

${ }^{118}$ K. Ashraf, M. H. M. Khir, J. O. Dennis and Z. Baharuddin, An energy pumping frequency increased vibration energy harvester, Power MEMS 2012 workshop-Atlanta, USA December 2-5, 2012.

${ }^{119}$ V. Kumar, Y. Singh, R. K. Prinshu and A. Islam, Low voltage charge pump for RF energy harvesting applications. Indian J. Sci. Technol. 9, (2016).

${ }^{120}$ M. Panyam, R. Masana and M. F. Daqaq, On approximating the effective bandwidth of bi-stable energy harvesters, Int. J. NonLinear. Mech. 67, 153 (2014).

${ }^{121}$ R. Dauksevicius et al., Frequency up-converting vibration energy harvester with multiple impacting beams for enhanced wideband operation at low frequencies. Procedia Eng. 87, 1517 (2014).

${ }^{122}$ M. A. Halim and J. Y. Park, Theoretical modeling and analysis of mechanical impact driven and frequency up-converted piezoelectric energy harvester for low-frequency and wide-bandwidth operation, Sens. Actuators A Phys. 208, 56 (2014).

${ }^{123}$ C. M. A. Lopes and C. A. Gallo, A review of piezoelectrical energy harvesting and applications, IEEE Int. Symp. Industrial Electronics (IEEE, New York, 2014), pp. 1284-1288, doi: 10.1109/ISIE.2014.6864799.

${ }^{124}$ M. A. Karami, J. R. Farmer and D. J. Inman, Parametrically excited nonlinear piezoelectric compact wind turbine, Renew. Energy 50, 977 (2013).

${ }^{125}$ L. H. Fang, S. I. S. Hassan, R. A. Rahim, M. Isa and B. Ismail, Exploring piezoelectric for sound wave as energy harvester, Energy Procedia 105, 459 (2017).

${ }^{126}$ L. H. Fang, S. I. S. Hassan, R. A. Rahim, M. Isa and B. Ismail, Charaterization of differents dimension piezoelectric transducer for sound wave energy harvesting, Energy Procedia 105, 836 (2017).

${ }^{127}$ M. A. Ilyas and J. Swingler, Piezoelectric energy harvesting from raindrop impacts, Energy 90, 796 (2015).

${ }^{128} \mathrm{M}$. A. Ilyas and J. Swingler, Towards a prototype module for piezoelectric energy harvesting from raindrop impacts, Energy 125, 716 (2017).

${ }^{129}$ N. A. K. Z. Abidin, N. M. Nayan, M. M. Azizan and A. Ali, Analysis of voltage multiplier circuit simulation for rain energy harvesting using circular piezoelectric, Mech. Syst. Signal Process. 101, 211 (2018).

${ }^{130} \mathrm{~S}$. Roundy and P. K. Wright, A piezoelectric vibration based generator for wireless electronics, Smart Mater. Struct. 13, 1131 (2004).

${ }^{131}$ J. Liang and W.-H. Liao, Energy flow in piezoelectric energy harvesting systems, Smart Mater. Struct. 20, 015005 (2011).

${ }^{132} \mathrm{Z}$. Yang, A. Erturk and J. Zu, On the efficiency of piezoelectric energy harvesters, Extrem. Mech. Lett. 15, 26 (2017).

${ }^{133}$ K. A. Cook-Chennault, N. Thambi and A. M. Sastry, Powering MEMS portable devices - a review of non-regenerative and regenerative power supply systems with special emphasis on piezoelectric energy harvesting systems, Smart Mater. Struct. 17, 043001 (2018).

${ }^{134}$ S. Meninger, J. O. Mur-Miranda, R. Amirtharajah, A. Chandrakasan and J. H. Lang, Vibration-to-electric energy conversion, IEEE Trans. Very Large Scale Integr. Syst. 9, 64 (2001).

${ }^{135}$ A. F. Diaz and R. M. Felix-Navarro, A semi-quantitative triboelectric series for polymeric materials: The influence of chemical structure and properties, J. Electrostat. 62, 277 (2004).

${ }^{136}$ Z. L. Wang, L. Lin, J. Chen, S. Niu and Y. Zi, Triboelectric Nanogenerators (Springer, Berlin, 2016). doi: 10.1007/978-3319-40039-6. 
${ }^{137}$ Y. Dong et al., Metallic MXenes: A new family of materials for flexible triboelectric nanogenerators, Nano Energy 44, 103 (2018).

${ }^{138}$ F. R. Fan, Z. Q. Tian and Z. Lin Wang, Flexible triboelectric generator, Nano Energy 1, 328 (2012).

${ }^{139}$ X.-S. Zhang et al., High-performance triboelectric nanogenerator with enhanced energy density based on single-step fluorocarbon plasma treatment, Nano Energy 4, 123 (2014).

${ }^{140} \mathrm{G}$. Zhu et al., Toward large-scale energy harvesting by a nanoparticle-enhanced triboelectric nanogenerator, Nano Lett. 13, 847 (2013).

${ }^{141} \mathrm{~S}$. Lee et al., Triboelectric nanogenerator for harvesting pendulum oscillation energy, Nano Energy 2, 1113 (2013).

${ }^{142}$ N. Jonassen, Electrostatistics (Springer, Boston, 2002), doi: 10.1007/978-1-4615-1073-4.

${ }^{143}$ Z. L. Wang, On Maxwell's displacement current for energy and sensors: The origin of nanogenerators, Materials Today 20, 74 (2017).

${ }^{144}$ J. S. Boland, J. D. M. Messenger, H. W. Lo and Y. C. Tai, Arrayed liquid rotor electret power generator systems, 18th IEEE Int. Conf. Micro Electro Mechanical Systems, 2005. MEMS 2005 (IEEE, New York, 2005), pp. 618-621, doi: 10.1109/memsys. 2005.1454005.

${ }^{145}$ R. T. Borno, Transpiration as a mechanism for mechanical and electrical energy conversion, University of Michigan, Horace H. Rackham School of Graduate Studies (2008).

${ }^{146}$ M. Salem, M. Salem, D. A. Borca-Tasciuc and M. M. Hella, Electrostatic MEMS converters with a switchable dielectric constant for micro-scale power generation, Proc. Int. Conf. Microelectronics, ICM (IEEE, New York, 2007), pp. 205-208, doi: 10.1109/ICM.2007.4497694.

${ }^{147}$ D. M. Taylor, Electrostatics 2003: Proceedings of the Electrostatics Conference of the Institute of Physics (Edinburgh, UK, 2003).

${ }^{148}$ R. Guillemet, P. Basset, D. Galayko and T. Bourouina, Combined optimization of electrical and mechanical parameters of in-plane and out-of-plane gap-closing electrostatic Vibration Energy Harvesters (VEHs), Procedia Eng. 5, 1172 (2010).

${ }^{149}$ T. Tsutsumino, Y. Suzuki and N. Kasagi, Electromechanical modeling of micro electret generator for energy harvesting, Transducers and Eurosensors '07 - 4th Int. Conf. Solid-State Sensors, Actuators and Microsystems (IEEE, New York, 2007), pp. 863-866, doi: 10.1109/SENSOR.2007.4300267.

${ }^{150}$ T. Sterken, P. Fiorini, K. Baert, R. Puers and G. Borghs, An electret-based electrostatic $\mu$-generator, Transducers 2003 12th Int. Conf. Solid-State Sensors, Actuators and Microsystems, Digest of Technical Papers 2, 1291 (2003).

${ }^{151}$ L. G. W. Tvedt, L. J. Blystad and E. Halvorsen, Simulation of an electrostatic energy harvester at large amplitude narrow and wide band vibrations, 2008 Symp. Design, Test, Integration and Packaging of MEMS/MOEMS (IEEE, New York, 2008), pp. 296301, doi: 10.1109/DTIP.2008.4753005

${ }^{152}$ H. Sarafian, Rotating elliptical parallel-plate capacitor and a transient electric circuit, 2008 Int. Conf. Computational Sciences and Its Applications (IEEE, New York, 2008), pp. 291-296, doi: 10.1109/ICCSA.2008.17.

${ }^{153}$ D. Sequeira, K. Coonley and B. Mann, Topological optimization of variable area plate capacitors for coupled electromechanical energy harvesters, J. Intell. Mater. Syst. Struct. 30, 2198 (2019), doi: $10.1177 / 1045389 X 19861792$.
${ }^{154}$ C. H. Haas and M. Kraft, Modelling and analysis of a MEMS approach to dc voltage step-up conversion, J. Micromech. Microeng. 14, S114 (2004).

${ }^{155}$ E. O. Torres and G. A. Rincón-Mora, Electrostatic energyharvesting and battery-charging CMOS system prototype, IEEE Trans. Circuits Syst. I Regul. Pap. 56, 1938 (2009).

${ }^{156}$ S. Boisseau, G. Despesse and B. A. Seddik, Electrostatic conversion for vibration energy harvesting, arXiv:1210.5191, doi:10.5772/51360.

${ }^{157}$ E. O. Torres and G. A. Rincón-Mora, Energy budget and highgain strategies for voltage-constrained electrostatic harvesters, Proc. IEEE Int. Symp. Circuits and Systems (IEEE, New York, 2009), pp. 1101-1104, doi: 10.1109/ISCAS.2009.5117952.

${ }^{158}$ Y. Naruse, N. Matsubara, K. Mabuchi, M. Izumi and S. Suzuki, Electrostatic micro power generation from low-frequency vibration such as human motion, J. Micromech. Microeng. 19, 094002 (2009).

${ }^{159}$ Y. Sakane, Y. Suzuki and N. Kasagi, Development of high-performance purfluorinated polymer electret, 2008 13th Int. Symp. Electrets (IEEE, New York, 2008), pp. 15-17, doi: 10.1109/ ISE.2008.4813996.

${ }^{160} \mathrm{P}$. Basset et al., A batch-fabricated and electret-free silicon electrostatic vibration energy harvester, J. Micromech. Microeng. 19, 115025 (2009).

${ }^{161}$ Y. Tada, Experimental characteristics of electret generator, using polymer film electrets, Jpn. J. Appl. Phys. 31, 846 (1992).

${ }^{162}$ R. Tashiro, N. Kabei, K. Katayama, E. Tsuboi and K. Tsuchiya, Development of an electrostatic generator for a cardiac pacemaker that harnesses the ventricular wall motion, J. Artif. Organs 5, 239 (2002).

${ }^{163}$ J. Boland, Y.-H. Chao, Y. Suzuki and Y. C. Tai, Micro electret power generator, IEEE Sixteenth Annual Int. Conf. Micro Electro Mechanical Systems (IEEE, New York, 2003), pp. 538-541, doi: 10.1109/memsys.2003.1189805.

${ }^{164}$ T. Genda, S. Tanaka and M. Esashi, Transducers high power electrostatic motor and generator using electrets, $2003-12$ th Int. Conf. Solid-State Sensors, Actuators and Microsystems, Digest of Technical Papers, Vol. 1 (IEEE, New York, 2003), pp. 492-495.

${ }^{165}$ D. Hoffmann, B. Folkmer and Y. Manoli, Fabrication, characterization and modelling of electrostatic micro-generators, $J$. Micromech. Microeng. 19, 094001 (2009).

${ }^{166}$ D. S. Nguyen, E. Halvorsen, G. U. Jensen and A. Vogl, Fabrication and characterization of a wideband MEMS energy harvester utilizing nonlinear springs, J. Micromech. Microeng. 20, 125009 (2010).

${ }^{167}$ T. Jiang et al., Theoretical study on rotary-sliding disk triboelectric nanogenerators in contact and non-contact modes, Nano Res. 9, 1057 (2016).

${ }^{168} \mathrm{P}$. Bai et al., Integrated multilayered triboelectric nanogenerator for harvesting biomechanical energy from human motions, ACS Nano 7, 3713 (2013).

${ }^{169}$ W. Xu et al., Environmentally friendly hydrogel-based triboelectric nanogenerators for versatile energy harvesting and selfpowered sensors, Adv. Energy Mater. 7, 1601529 (2017).

${ }^{170}$ T.-C. Hou et al., Triboelectric nanogenerator built inside shoe insole for harvesting walking energy, Nano Energy 2, 856 (2013).

${ }^{171}$ Y. Xie et al., Multi-layered disk triboelectric nanogenerator for harvesting hydropower, Nano Energy 6, 129 (2014).

${ }^{172}$ S. Park et al., Rotating triboelectric generator using sliding contact and noncontact from 1D fiber friction, Nano Energy 33, 184 (2017). 
${ }^{173} \mathrm{~W}$. Du et al., A three dimensional multi-layered sliding triboelectric nanogenerator, Adv. Energy Mater. 4, 1301592 (2014).

${ }^{174}$ Y. Mao, D. Geng, E. Liang and X. Wang, Single-electrode triboelectric nanogenerator for scavenging friction energy from rolling tires, Nano Energy 15, 227 (2015).

${ }^{175}$ Y.-C. Lai et al., Single-thread-based wearable and highly stretchable triboelectric nanogenerators and their applications in cloth-based self-powered human-interactive and biomedical sensing, Adv. Funct. Mater. 27, 1604462 (2017).

${ }^{176} \mathrm{~B}$. Meng et al., A transparent single-friction-surface triboelectric generator and self-powered touch sensor, Energy Environ. Sci. 6, 3235 (2013).

${ }^{177}$ N. Kaur et al., Effective energy harvesting from a single electrode based triboelectric nanogenerator, Sci. Rep. 6, 38835 (2016).

${ }^{178}$ J. Park, A. Y. Choi, C. J. Lee, D. Kim and Y. T. Kim, Highly stretchable fiber-based single-electrode triboelectric nanogenerator for wearable devices, RSC Adv. 7, 54829 (2017).

${ }^{179} \mathrm{G}$. Zhu et al., Triboelectric-generator-driven pulse electrodeposition for micropatterning, Nano Lett. 12, 4960 (2012).

${ }^{180} \mathrm{Y}$. Su et al., Wind energy harvesting and self-powered flow rate sensor enabled by contact electrification, J. Phys. D. Appl. Phys. 49, 215601 (2016).

${ }^{181} \mathrm{~J}$. He et al., Triboelectric-piezoelectric-electromagnetic hybrid nanogenerator for high-efficient vibration energy harvesting and self-powered wireless monitoring system, Nano Energy 43, 326 (2018).

${ }^{182} \mathrm{H}$. Askari et al., A hybridized electromagnetic-triboelectric selfpowered sensor for traffic monitoring: Concept, modelling, and optimization, Nano Energy 32, 105 (2017).

${ }^{183} \mathrm{H}$. Shao et al., Multifunctional power unit by hybridizing contact-separate triboelectric nanogenerator, electromagnetic generator and solar cell for harvesting blue energy, Nano Energy 39, 608 (2017).

${ }^{184}$ R. T. Aljadiri, L. Y. Taha and P. Ivey, Electrostatic energy harvesting systems: A better understanding of their sustainability, $J$. Clean Energy Technol. 5, 409 (2017).

${ }^{185} \mathrm{~B}$. C. Yen, A variable-capacitance vibration-to-electric energy harvester, IEEE Trans. Circuits Syst. 8.

${ }^{186} \mathrm{Z}$. Deng and M. J. Dapino, Review of magnetostrictive vibration energy harvesters, Smart Mater. Struct. 26, 103001 (2017).

${ }^{187}$ E. W. Lee, Magnetostriction and magnetomechanical effects, Reports Prog. Phys. 18, 305 (1955).

${ }^{188}$ I. Kholmetska, J. Chleboun and P. Krejčí, Numerical modeling of Galfenol magnetostrictive response, Appl. Math. Comput. 319, 527 (2018)

${ }^{189}$ L. Ajroudi et al., Magnetic, electric and thermal properties of cobalt ferrite nanoparticles, Mater. Res. Bull. 59, 49 (2014).

${ }^{190}$ B. Yan, C. Zhang and L. Li, Magnetostrictive energy generator for harvesting the rotation of human knee joint, $A I P A d v .8$, 056730 (2018).

${ }^{191}$ P. Martins and S. Lanceros-Méndez, Polymer-based magnetoelectric materials, Adv. Funct. Mater. 23, 3371 (2013).

${ }^{192}$ R.-C. Luo, F. Wang and Y. Liu, An imaging tactile sensor with magnetostrictive transduction, eds. D. P. Casasent and E. L. Hall, Vol. 0521, (International Society for Optics and Photonics, 1985), p. 264.

${ }^{193}$ J. Hu, F. Xu, A. Q. Huang and F. G. Yuan, Optimal design of a vibration-based energy harvester using magnetostrictive material (MsM), Smart Mater. Struct. 20, 015021 (2011).
${ }^{194}$ H. Kwun and K. A. Bartels, Magnetostrictive sensor technology and its applications, Ultrasonics 36, 171 (1998).

${ }^{195}$ B. Yan, C. Zhang and L. Li, Magnetostrictive energy harvester with adjustable-air gap for low frequency human walking, IECON 2017 - 43rd Annual Conf. IEEE Industrial Electronics Society (IEEE, New York, 2017), pp. 2576-2581, doi: 10.1109/ IECON.2017.8216433.

${ }^{196}$ B. Yan, C. Zhang and L. Li, Design and fabrication of a highefficiency magnetostrictive energy harvester for high-impact vibration systems, IEEE Trans. Magn. 51, 1 (2015).

${ }^{197}$ B. Yan, C. Zhang, L. Li, H. Zhang and S. Deng, Design and construction of magnetostrictive energy harvester for power generating floor systems, 2015 18th Int. Conf. Electrical Machines and Systems (ICEMS) (IEEE, New York, 2015), pp. 409-412, doi: 10.1109/ICEMS.2015.7385068.

${ }^{198}$ D. Davino, P. Krejčí, A. Pimenov, D. Rachinskii and C. Visone, Analysis of an operator-differential model for magnetostrictive energy harvesting, Commun. Nonlinear Sci. Numer. Simul. 39, 504 (2016).

${ }^{199}$ H. Jafari, A. Ghodsi, S. Azizi and M. R. Ghazavi, Energy harvesting based on magnetostriction, for low frequency excitations, Energy 124, 1 (2017).

${ }^{200}$ S. Dey, D. Roy, S. Patra and T. Santra, Performance of a modified magnetostrictive energy harvester in mechanical vibration, Heliyon 5, e01135 (2019).

${ }^{201}$ Z. Yang, Y. Tan and J. Zu, A multi-impact frequency upconverted magnetostrictive transducer for harvesting energy from finger tapping, Int. J. Mech. Sci. 126, 235 (2017).

${ }^{202}$ Z.-W. Fang, Y.-W. Zhang, X. Li, H. Ding and L.-Q. Chen, Integration of a nonlinear energy sink and a giant magnetostrictive energy harvester, J. Sound Vib. 391, 35 (2017).

${ }^{203}$ K.-F. Xu, Y.-W. Zhang, Y.-N. Lu and L.-Q. Chen, Dynamic analysis of nonlinear energy sink and gaint magnetostrictive material energy harvester on account of nonlinear output frequency response functions, 2018 10th Int. Conf. Modelling, Identification and Control (ICMIC) (IEEE, New York, 2018) pp. 1-3, doi: 10.1109/ICMIC.2018.8529952.

${ }^{204} \mathrm{M}$. Al Janaideh and O. Aljanaideh, Further results on open-loop compensation of rate-dependent hysteresis in a magnetostrictive actuator with the Prandtl-Ishlinskii model, Mech. Syst. Signal Process. 104, 835 (2018).

${ }^{205}$ D. Davino, A. Giustiniani and C. Visone, Effects of hysteresis and eddy currents in magnetostrictive harvesting devices, Phys. $B$ Condens. Matter 407, 1433 (2012).

${ }^{206}$ S. Mohammadi and A. Esfandiari, Magnetostrictive vibration energy harvesting using strain energy method, Energy 81, 519 (2015).

${ }^{207}$ L. Wang and F. G. Yuan, Vibration energy harvesting by magnetostrictive material, Smart Mater. Struct. 17, 045009 (2008).

${ }^{208}$ S. Zhou, J. Cao, D. J. Inman, J. Lin and D. Li, Harmonic balance analysis of nonlinear tristable energy harvesters for performance enhancement, J. Sound Vib. 373, 223 (2016).

${ }^{209}$ P. Pillatsch, E. M. Yeatman and A. S. Holmes, A piezoelectric frequency up-converting energy harvester with rotating proof mass for human body applications, Sen. Actuators A Phys. 206, 178 (2014).

${ }^{210}$ T. Ni, L. Zuo and A. Kareem, Assessment of energy potential and vibration mitigation of regenerative tuned mass dampers on wind excited tall buildings, Volume 1: 23rd Biennial Conf. Mechanical Vibration and Noise, Parts A and B (ASME, 2011), pp. 333-342, doi: 10.1115/DETC2011-48728. 